\title{
Climate Wise
}

\section{Case Studu Compendium: Heport 1}

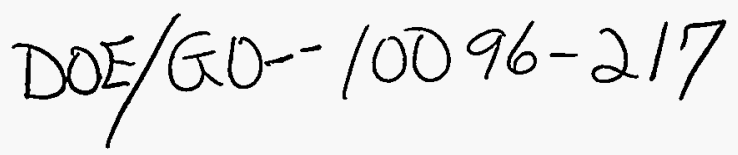

\section{DISCLAIMER}

This report was prepared as an account of work sponsored by an agency of the United States Government. Neither the United States Government nor any agency thereof, nor any of their employees, makes any warranty, express or implied, or assumes any legal liability or responsibility for the accuracy, completeness, or usefulness of any information, apparatus, product, or process disclosed, or represents that its use would not infringe privately owned rights. Reference herein to any specific commercial product, process, or service by trade name, trademark, manufacturer, or otherwise does not necessarily constitute or imply its endorsement, recommendation, or favoring by the United States Government or any agency thereof. The views and opinions of authors expressed herein do not necessarily state or reflect those of the United States Government or any agency thereof.

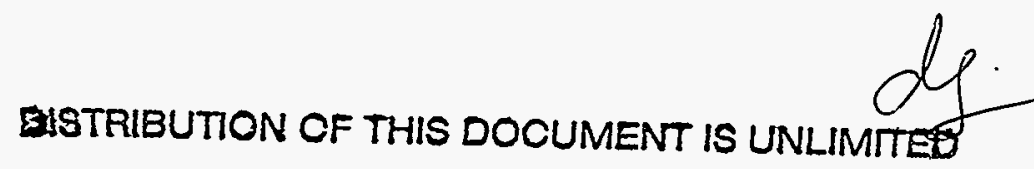




\section{DISCLAMMER}

Portions of this document may be illegible in electronic image products. Images are produced from the best available original document. 


\section{Introduction}

\section{Climate Wise Partners}

Coors Brewing Company........ 4

Dow Chemical Company.......... 5

DuPont ................ 6

ETTA Industries . . . . . . . . . 7

Fetzer Vineyards............ 8

General Motors Corporation ....... 9

Georgia-Pacific Corporation ....... 10

Johnson \& Johnson . . . . . . . . . . 11

Lockheed Martin . . . . . . . . . . . . 12

Majestic Metals, Inc. . . . . . . . . 13

Quad/Graphics ............. 14

Weyerhaeuser Company ........ 15

\section{Industrial Case Studies}

SIC 2000: Food and Kindred

Products

Good Humor Unilever. . . . . . . . . 18

Mar-Jac, Inc. . . . . . . . . . . . 20

Oregon State University Industrial

Assessment Center . . . . . . . . 21

South Dakota State University

Industrial Assessment Center . . . . 22

Tillamook Country Smoker. . . . . . . 23

SIC 2200: Textile Mill Products

University of Missouri at Rolla

Industrial Assessment Center . . . . . 24

SIC 2400: Lumber and Wood

Products, except Furniture

SDS Lumber Company . . . . . . . . . . 26

University of Arkansas at Little Rock

Industrial Assessment Center . . . . . 28

SIC 2600: Paper and Allied Products

Blandin Paper Company . . . . . . . . 30

Bowater Incorporated . . . . . . . . . . 32

SIC 2700: Printing, Publishing, and Allied Industries

Saratoga Springs Imaging .34
SIC 2800: Chemicals and Allied Products

DuPont ............... 36

FMC Corporation . . . . . . . . 38

Oklahoma State University Industrial

Assessment Center . . . . . . . . . 40

PPG Industries . . . . . . . . . . 42

SIC 3000: Rubber and Miscellaneous Plastic Products

San Francisco State University

Industrial Assessment Center . . . . . 44

SIC 3300: Primary Metal Industries

Bradley University Industrial

Assessment Center . . . . . . . . . 45

California Steel Industries, Inc. . . . . 46

Decatur Foundry, Inc. . . . . . . . . . 48

Florida Steel . . . . . . . . . 50

Iowa State University Industrial

Assessment Center . . . . . . . . . 52

Republic Engineered Steels, Inc. . . . 54

SIC 3400: Fabricated Metal

Products, except Machinery and

Transportation

Arizona State University Industrial

Assessment Center . . . . . . . . 56

Colorado State University Industrial

Assessment Center . . . . . . . . 58

Greenfield Industries . . . . . . . . 60

Hyde Tools. . . . . . . . . . . . . . . . 62

Ilco Unican Corporation . . . . . . . . . 64

San Diego University Industrial

Assessment Center

SIC 3500: Industrial and

Commercial Machinery and

Computer Equipment

Compaq Computer Corporation ....66 66

SIC 5100 Wholesale Trade

NIKE, Inc 68

71 Appendix 


\section{Climate Wise Case Study Reference Table}

\begin{tabular}{lllr}
\hline & State & Technology/Action & Page \\
\hline SIC 2000: Food \& Kindred Products & & & 18 \\
\hline Good Humor Unilever & MA & Ammonia refrigeration system & 20 \\
\hline Mar-Jac, Inc. & GA & Direct-fired gas water heater & 21 \\
\hline $\begin{array}{l}\text { Oregon State University IAC- } \\
\text { Manufacturer of Fluid Dairy Products }\end{array}$ & OR & $\begin{array}{l}\text { High-efficiency motors, improved compressed air } \\
\text { system, heat recovery, insulating steam lines }\end{array}$ \\
$\begin{array}{l}\text { South Dakota State University IAC- } \\
\text { Manufacturer of Frozen Bakery Products }\end{array}$ & SD & $\begin{array}{l}\text { Energy-efficient lights and motors, insulated baking } \\
\text { ovens, improved compressed air system }\end{array}$ \\
\hline Tillamook Country Smoker & OR & Heat-recovery system & 22 \\
\hline
\end{tabular}

\section{SIC 2200: Textile Mill Products}

University of Missouri at Rolla IAC-

MO

Energy-efficient lights and motors, heat containment,

Processor of Denim Jeans

air compressor system modifications, electric boiler

\section{SIC 2400: Lumber \& Wood Products, except Furniture}

SDS Lumber Company

University of Arkansas at Little Rock IAC- AR

Producer of Preserved Railroad Cross Ties
WA Variable-speed drive

AR Energy-efficient lights and motors, repairing and

28 insulating steam lines, insulated process tanks, segmented belts in motors

\section{SIC 2600: Paper \& Allied Products}

\begin{tabular}{l}
\hline Blandin Paper Company \\
\hline Bowater Incorporated
\end{tabular}

\section{SIC 2700: Printing, Publishing, \& Allied Industries}

Saratoga Springs Imaging

WI

Silver reclamation and wash system

\section{SIC 2800: Chemicals \& Allied Products}

\begin{tabular}{|c|c|c|c|}
\hline DuPont & NJ & Steam trap inspection & 36 \\
\hline F'MC Corporation & $\mathrm{TX}$ & Methanol recovery system using steam distillation & 38 \\
\hline $\begin{array}{l}\text { Oklahoma State University IAC- } \\
\text { Manufacturer of Refined Waxes }\end{array}$ & OK & Energy-efficient lights, steam traps, heat recovery & 40 \\
\hline PPG Industries & $\mathrm{OH}$ & Ultrafiltration/reverse osmosis & 4 \\
\hline
\end{tabular}




\begin{tabular}{|c|c|c|c|}
\hline & State & Technology/Action & Page \\
\hline \multicolumn{4}{|c|}{ SIC 3000: Rubber \& Miscellaneous Plastic Products } \\
\hline $\begin{array}{l}\text { San Francisco State University IAC- } \\
\text { Manufacturer of Injection-Molded Plastic Parts }\end{array}$ & $\mathrm{CA}$ & $\begin{array}{l}\text { Variable-speed drives, notched V-belts on motor } \\
\text { drives, improved compressed air system }\end{array}$ & 44 \\
\hline \multicolumn{4}{|l|}{ SIC 3300: Primary Metal Industries } \\
\hline $\begin{array}{l}\text { Bradley University IAC- } \\
\text { Manufacturer of Aluminum Castings }\end{array}$ & IL & Energy-efficient lights and motors & 45 \\
\hline California Steel Industries, Inc. & $\mathrm{CA}$ & Variable-speed drives & 46 \\
\hline Decatur Foundry, Inc. & IL & Infrared mold wash coating system & 48 \\
\hline Florida Steel & FL & CONSTEEL scrap preheating method & 50 \\
\hline $\begin{array}{l}\text { Iowa State University IAC- } \\
\text { Producer of Iron Castings }\end{array}$ & IA & $\begin{array}{l}\text { Energy- efficient lights and motors, improved } \\
\text { compressed air systems }\end{array}$ & 52 \\
\hline Republic Engineered Steels, Inc. & $\mathrm{OH}$ & Scrap metal recycling and water reuse & 54 \\
\hline
\end{tabular}

\section{SIC 3400: Fabricated Metal Products, except Machinery and Transportation}

\begin{tabular}{lclr}
\hline $\begin{array}{l}\text { Arizona State University IAC- } \\
\text { Metal Parts Manufacturer }\end{array}$ & AZ & $\begin{array}{l}\text { Steam jacket heaters, energy-efficient lighting, } \\
\text { synthetic lubricants }\end{array}$ \\
\hline $\begin{array}{l}\text { Colorado State University IAC- } \\
\text { Manufacturer of Screw Machine Products }\end{array}$ & CO & $\begin{array}{l}\text { Energy-efficient motors and lights, insulated hot } \\
\text { tanks and plating lines }\end{array}$ \\
\hline Greenfield Industries & MA & Vacuum furnace & 56 \\
\hline Hyde Tools & MA & Energy-efficient lighting, wastewater recycling & 60 \\
\hline Ilco Unican Corporation & NC & High-pressure aqueous cleaning system & 62 \\
\hline $\begin{array}{l}\text { San Diego University IAC- } \\
\text { Manufacturer of Transducers }\end{array}$ & CA & $\begin{array}{l}\text { Energy-efficient lights and motors, chiller, improved } \\
\text { compressed air system, insulated hot water lines }\end{array}$ \\
\hline
\end{tabular}

\section{SIC 3500: Industrial \& Commercial Machinery \& Computer Equipment}

Compaq Computer Corporation TX Energy-efficient lights and HVAC retrofits 66

\section{SIC 5100: Wholesale Trade}

NIKE, Inc.




\section{Introduction}

The Climate Wise Case Study Compendium showcases how industries across the nation have made their operations leaner and cleaner. The case studies focus on projects that require minimal capital investment, have a high return on investment, and result in cost savings and additional benefits for the companies. Some of the projects are completed in partnership with the Federal Government, utilities, and state and local government offices.

The U.S. Department of Energy's Office of Industrial Technologies (OIT) developed this Compendium for the Climate Wise program to show businesses the proven value of undertaking energy efficiency and pollution prevention measures. The benefits of undertaking these measures include significant cost savings, safer work environments, regulatory compliance, improved environmental performance, improved employee morale, reduced liability, and positive community relations.

\section{Climate Wise}

Climate Wise, a private-public partnership program, is a key Federal initiative to return greenhouse gas emissions to 1990 levels by 2000. The program is a collaborative effort supported by OIT at the U.S. Department of Energy (DOE) and the Office of Policy, Planning and Evaluation at the U.S. Environmental Protection Agency (EPA).

Climate Wise encourages industrial companies to take innovative approaches to turning energy efficiency and environmental performance into corporate assets.

Companies enroll by completing a one-page Climate Wise Partnership Agreement. Then, companies submit an Action Plan, detailing their strategy for increasing efficiency and reducing emissions. By joining the program, Climate Wise partners agree to initiate, expand, or accelerate cost-effective measures to improve efficiency and protect the environment, thus saving their company money while improving productivity.
This Case Study Compendium is one of several Climate Wise tools available to help interested companies identify cost-effective options. Climate Wise also offers the Climate Wise Opportunities Assessment Guide, which provides companies with a list of costeffective actions and the protocols for ascertaining their feasibility in an organization.

\section{Organization of the Compendium}

The Compendium is divided into three sections: this Introduction (Section 1), Climate Wise Partners (Section 2), and Industrial Case Studies (Section 3). This first edition of the Climate Wise Case Study Compendium provides information on stateof-the-art technologies and innovative corporate approaches to energy efficiency and pollution prevention.

Section 2-Climate Wise Partnersidentifies some of the partner companies that have joined Climate Wise and highlights the actions they are taking to reduce harmful greenhouse gas emissions while increasing productivity. As part of their Climate Wise pledge, these companies are participating in other voluntary Federal programs, such as Motor Challenge, Green Lights, and Waste Wise. They are also developing their own innovative programs to reduce greenhouse gases and save energy.

Section 3-Industrial Case Studiesprovides 30 case studies organized by Standard Industrial Classification codes. A focus group of industry partners, held in June 1995, provided insight into the type of information that would be useful in a case
CLIMATE WISE CODIRECTORS

Amy Manheim

U.S. Department of Energy

Office of Industrial

Technologies, EE-24

1000 Independence Avenue, SW

Washington, DC 20585

Phone: (202) 586-1507

Fax: (202) 586-1605

Gerald Kotas

U.S. Department of Energy

Golden Field Office

1617 Cole Boulevard

Golden, Colorado 80401

Phone: (303) 275-4714

Fax: (303) $275-4790$

Pamela Herman

U.S. Environmental Protection Agency

Office of Policy, Planning and Evaluation 401 M Street, SW

Washington, DC 20460

Phone: (202) 260-4407

Fax: (202) 260-0512 
study. This information includes cost details, management approach and impetus for the project, community benefits, cross-industry applications, and process flow diagrams. OIT's Climate Wise program worked closely with several companies highlighted in $\mathbf{1 0}$ of the case studies to gather these details, when available.

Other case studies are from DOE's Industrial Assessment Centers. These centers, located in universities throughout the United States, conduct assessments for small- and medium-sized manufacturers at no cost to the company. After an assessment, the center recommends actions that will improve productivity, reduce waste, and save energy at the plant. These case studies describe recommendations made by several of the Industrial Assessment Centers and the savings companies are realizing from implementing some of those recommendations.

The remaining case studies were compiled from a variety of sources and reformatted for inclusion in the Compendium. When available, a contact for more information is provided.

By reading this Compendium, companies will see what others are doing to cut energy costs, improve processes, reduce waste, and realize productivity gains. Climate Wise hopes that this Compendium facilitates the decision-making process for those companies interested in adopting energy efficiency and pollution prevention technologies.

As new case studies are collected or researched, the Compendium will be expanded to ensure up-to-date and comprehensive information. Please call one of the Climate Wise Codirectors listed on the front page if you have any questions or concerns pertaining to this document or Climate Wise.

You may also access this document electronically on the World Wide Web at www.oit.doe.gov/access/climate/ 


\section{Climate Wise Partners}

The Climate Wise program is helping many U.S. industries find creative ways to improve their competitiveness while reducing greenhouse gas emissions. Many companies have pledged their commitment to Climate Wise and are adopting comprehensive approaches to reducing emissions. Companies are improving industrial processes, substituting fuels and raw materials, and participating in other Federal voluntary programs. The following fact sheets describe what the earliest Climate Wise companies are doing to enhance energy efficiency and prevent pollution.

The Climate Wise companies highlighted in this section are:

\section{Coors Brewing Companl}

Dow Chemical Company

DuPont

ETth Industries
Felzer Vinelards

General Motors Corporation

Georgia-Pacific Corporation

Johnson \& Johnson
Lochheed Martin

Majestic Metals, Inc.

Quvad/Graphics

Weyerhaeuser Company 


\section{Coors Brewing Compan!}

\section{The Company}

Coors Brewing Company makes malt-based beverages, including Coors Light, Original Coors, George Killian's Irish Red Lager, Zima Clearmalt, and other premium beers. Coors is the third largest brewer in the United States and the ninth largest in the world. The company employs more than 6000 people. Coors' beverages are sold nationwide and in 24 international markets.

LOCATION

Golden, Colorado

INDUSTRY

Food and Beverage

APPLICABLE SIC CODE

2082

\section{Pledge Highlights}

Coors became a Climate Wise partner in March 1995. For Coors, Climate Wise serves as an umbrella program for its existing energy efficiency and pollution prevention programs. Coors has a long-standing commitment to environmental and energy projects that make competitive sense. The company:

- Participates in EPA's 33/50 program and has achieved more than a $90 \%$ reduction in the emission of air toxics from its production facilities

- Participates in EPA's Waste Wise program by reducing packaging wastes and weights
- Uses alternative fuel vehicles at the Golden, Colorado, production site

- Promotes the ultraviolet-cured ink and overcoat process for aluminum cans through the assistance of a $\mathrm{NICE}^{3}$ grant

- Has researched a low VOC internal coating for can manufacturing that could save energy.

The company is working with DOE and EPA through Colorado's Pollution Prevention Partnership and the Climate Wise program to analyze opportunities to reduce energy consumption per unit of product. 


\section{The Dow Chemical Companu}

\section{The Company}

The Dow Chemical Company manufactures and supplies more than 2400 product families, including chemicals and performance products, plastics, hydrocarbons and energy, and consumer specialties.

The company operates 113 manufacturing sites in 30 countries and employs about 41,000 people around the world.

\section{Pledge Highlights}

The Dow Chemical Company joined Climate Wise in September 1995. Dow supports the program's efforts to offer industry the chance to participate in a wide range of voluntary programs to achieve sustainable environmental progress.

As part of its commitment to the Climate Wise program, Dow will:

- Report its global greenhouse gas emissions and reductions through the Energy Policy Act's 1605(b) database

- Reduce Btu use per pound of product manufactured by $2 \%$ a year between 1992 (base year) and 2000

- Reduce $\mathrm{NO}_{\mathrm{x}}$ generation using technologies such as dry $\mathrm{NO}_{\mathrm{x}}$ combusters or low $\mathrm{NO}_{\mathrm{x}}$ burners for new boilers and furnaces

- Develop alternatives for chlorofluorocarbons and hydrochlorofluorocarbons in its plastic foam products, and continue to research ways to use naturally occurring $\mathrm{CO}_{2}$ as a blowing agent substitute.
In addition, Dow pledges to perform the following voluntary activities to promote further reductions in greenhouse gas emissions.

- Continue to participate in EPA's 33/50 program, under which Dow has reduced emissions by $51 \%$

- Promote insulation products that help reduce greenhouse gas emissions

- Include energy efficiency focus in its environmental policies

- Improve energy efficiency through cogeneration and recycling efforts

- Continue participation in DOE's Motor Challenge program

- Communicate its progress to EPA/DOE on these energy-related goals, as well as to the public and key company stakeholders.

Dow has an established energy management structure that guides its participation in Climate Wise. For example, Dow's Global Energy Policy and Conservation Strategy Team develops plans to reduce corporate energy use worldwide. In addition, teams dedicated to climate change and energy efficiency management help direct Dow's actions in the environmental and energy arenas.
LOCATION

Midland, Michigan

INDUSTRY

Chemicals

APPLICABLE SIC CODES

$2800,3089,3339$ 
Climate Wise Partners

\section{DuPont}

\section{The Company}

DuPont is the 10th largest industrial corporation in the country and the 26th largest in the world.

With annual sales of more than $\$ 39.3$ billion, DuPont has approximately 107,000 employees. About

half of the company's sales are outside the United States. DuPont operates 150 plants in its chemicals

and specialties businesses. DuPont also operates 5 petroleum refineries and 20 natural gas

processing plants through its energy subsidiary, Conoco.

\section{LOCATION}

Wilmington, Delaware

INDUSTRY

Chemicals, Petroleum Refining

APPLICABLE SIC CODES

2800,2911

\section{Pledge Highlights}

DuPont was the first company to sign on to the Climate Wise program. Its actions will reduce greenhouse gas emissions by an estimated 18 million metric tons of $\mathrm{CO}_{2}$ equivalent by 2000 . Through energy efficiency improvements, the company expects to save $\$ 31$ million annually. DuPont pledges to:

- Improve energy use in manufacturing facilities by $15 \%$ per pound of product by 2000

- Eliminate nitrous oxide emissions by implementing projects that will destroy or recapture it for beneficial use

- Reduce hydrofluorocarbon-23 and perfluorocarbon emissions

- By the end of 1995, eliminate the production for sale of chlorofluorocarbons.
DuPont has an established energy management structure that will help the company fulfill its Climate Wise pledge. The key organizational driver is DuPont's Corporate Energy Leadership Team, jointly led by senior vice presidents from the chemical and energy operations. The team also comprises representatives from the major internal business and technical functions and from external energy suppliers. DuPont's strong commitment to energy efficiency is reflected in its 1992 Energy Utilization Policy, which requires continuous improvement in energy use. The company also publishes an annual Environmental Progress Report that tracks the achievements of its energy efficiency and pollution prevention programs. 


\section{ETTh Industries}

\section{The Company}

ETTA Industries is a privately held Colorado corporation, operating since 1986 and incorporated in 1987. The company charter was to develop and manufacture state-of-the-art fluorescent lighting technology. To date, ETTA has generated several U.S. and international patents on electronic ballast technology. Customers include NASA, Boeing, the Pentagon/Defense Mapping Department, and Compaq Computers.

In 1992, ETTA Industries received an energy conservation award from Boulder County (Colorado) for its technology and contribution to energy conservation. In 1994, ETTA received an award from the Denver Business Journal and Bank One for introducing one of Colorado's most innovative new products: a fluorescent dimming ballast with a wireless fiber-optic dimmer that senses sunlight.

\section{Pledge Highlights}

In January 1995, ETTA Industries joined Climate Wise as the first small business partner. ETTA pledges to:

- Continue participation in EPA's Green Lights program. In 1992, ETTA installed its electronic ballasts and controls in the company's 10,000-square-foot facility. The lighting upgrades completed by ETTA will result in an annual energy savings of $18,464 \mathrm{kWh}$ and prevent the emission of 20,380 pounds of $\mathrm{CO}_{2}, 30,571$ grams of $\mathrm{SO}_{2}$, and 29,644 grams of $\mathrm{NO}_{\mathrm{x}}$.

- Install energy-efficient lighting in its new 20,000-square-foot facility and make other changes to improve the facility's energy efficiency.
As a manufacturer of energy-efficient lighting products, ETTA is well positioned to contribute to national and international energy savings and corresponding $\mathrm{CO}_{2}$ emission reductions. The company's goal is to capture at least $5 \%$ of the global market share of electronic ballasts by 2000 . Achieving this goal will translate to sales of about 20 million electronic ballasts per year, saving 4 billion $\mathrm{kWh}$ of electrical energy in 2000 and preventing more than 6 billion pounds of $\mathrm{CO}_{2}$ emissions.

In December 1994, ETTA received a guaranteed loan from the Small Business Administration. ETTA is using this loan to increase manufacturing capacity, which will allow the company to increase production of technology and other products that contribute to energy efficiency and pollution prevention.
LOCATION

Boulder, Colorado

INDUSTRY

Electronics

APPLICABLE SIC CODE 3600 
Climate Wise Partners

\section{Felzer Vineluards}

\section{The Company}

Fetzer Vineyards is a leading producer of quality wines. It buys all its grapes from the Fetzer family, which under the newly established company, Kohn Properties, is the largest producer of organically grown grapes in Mendocino County, California.

LOCATION

Redwood Valley, California

INDUSTRY

Food and Beverage

APPLICABLE SIC CODE

\section{Pledge Highlights}

In November 1994, Fetzer Vineyards became

a Climate Wise partner. Fetzer is active in several areas to reduce greenhouse gas emissions and has already realized tangible cost savings and waste reduction. The winery pledges to continue its efforts to become the most sustainable operation possible. Fetzer has committed to:

- Reduce power usage more than $50 \%$ by 2050

- Provide company transportation using buses powered by electricity

- Make its packaging from $100 \%$ recycled material and nontoxic, environmentally safe inks

- Convert service vehicles to solar-powered electric or natural gas vehicles

- Become $100 \%$ solar powered throughout the company by 2015

- Eliminate the use of toxic chemicals by 2000 . 


\section{General Motors Corporation}

\section{The Company}

General Motors (GM) Corporation is one of the world's largest industrial enterprises. GM manufactures cars and trucks under a variety of nameplates, including Cadillac, Chevrolet, Buick, Saturn, Oldsmobile, Pontiac, Geo, and GMC Truck. The company was founded in 1908 in Flint, Michigan, and today employs about 700,000 people. GM has approximately 8900 motor vehicle dealers in the United States and about 6500 outlets overseas.

\section{Pledge Highlights}

GM joined the Climate Wise program in March 1995. GM strongly supports voluntary programs, such as Climate Wise, as the best approach for addressing environmental challenges and improving energy efficiency. Environmentally responsible manufacturing is a key factor to GM's long-term success. As a result of its Climate Wise partnership, GM pledges to:

- Launch an outreach program to involve GM's suppliers in energy efficiency initiatives

- Work with DOE national laboratories to identify additional cost-effective energy efficiency and pollution prevention actions

- Sign up the North American Truck Group and Saturn Corporation to participate in EPA's Green Lights program. Participation in Green Lights may be expanded to include all of GM.

- Continue participation in DOE's Motor Challenge program and EPA's Waste Wise program
- Accelerate the implementation of a benchmarking project designed to identify the 10 least energy-efficient facilities, audit their operations, and implement the identified recommendations of the audit

- Accelerate the Powerhouse Evaluation Study to identify opportunities at $\mathbf{5 0}$ facilities to shut down or convert plant boilers to cleaner burning fuels and provide plant heat more efficiently.

Recently, GM combined its long-standing environmental and energy operations to more effectively coordinate the company's efforts in these areas. GM's Environmental and Energy staff is translating its Environmental Principles into effective strategies and policies. These principles provide a focal point for many environmental initiatives in progress throughout the corporation.

Each of GM's North American facilities reports its monthly energy usage to a central database. Although the corporation does not set annual energy efficiency improvement targets, implementing energy cost-reduction projects is essential for each facility to reduce its operating costs and remain competitive.
LOCATION

Detroit, Michigan

INDUSTRY

Automotive

APPLICABLE SIC CODES

$3711,3714,6141$,

$6153,6159,6331$ 
Climate Wise Partners

\section{Georgia-Pacific Corporation}

\section{The Company}

Georgia-Pacific Corporation is one of the largest U.S. producers of building and paper products.

Almost half of the company's net sales are paper related. The company owns about 5.8 million acres of timberland in North America.

LOCATION

Atlanta, Georgia

INDUSTRY

Forest and Paper Products

APPLICABLE SIC CODE

2621

\section{Pledge Highlights}

In August 1994, Georgia-Pacific accepted the Climate Wise challenge to help the nation reduce greenhouse gas emissions. The company has pledged to:

- Reduce waste wood sent to landfills

- Increase carbon sequestration through increased biomass fuel use and sustainable forestry practices

- Implement transportation actions, including containerboard and pulp trading and backhauling

- Collect site-specific energy database per unit of production

- Retrofit five facilities with energyefficient lighting by December 1995.
Georgia-Pacific formed an energy management team and assigned energy consultants throughout its facilities to oversee and implement the Climate Wise program. Employees also participate on energy teams. The company has already developed a lighting efficiency plan. To coordinate the commitments of the Climate Wise program, Georgia-Pacific appointed a Climate Wise Steering Committee. 


\section{Johnson f John50ח}

\section{The Company}

Johnson \& Johnson, employing more than 80,000 people, is the world's largest health care products company. It is well known as the manufacturer of the pain reliever, Tylenol, and the contact lens brand, Acuvue. The company operates in three sectors: consumer products (e.g., Band-Aid and Reach), professional products (surgical instruments, joint replacements), and pharmaceuticals.

\section{Pledge Highlights}

In August 1994, Johnson \& Johnson became a Climate Wise partner and committed to:

- Achieve a $10 \%$ equivalent energy reduction goal by 1996

- Remain active in EPA's Green Lights and Waste Wise programs

n Participate in DOE's Motor Challenge program

n Eliminate the use of chlorofluorocarbons in products and processes

n Reduce office waste by 50\% by 1996
- Reduce nonhazardous waste production by $50 \%$ and hazardous waste production by $10 \%$

- Conduct annual Earth Day and Energy Awareness Week events to heighten awareness of energy usage and reduction opportunities for employees at home and in the workplace.

Johnson \& Johnson communicates its climate change activities worldwide so that its facilities overseas learn from U.S. actions. Johnson \& Johnson reports the results of its efforts on an annual basis to DOE and EPA.
LOCATION

New Brunswick, New Jersey

\section{INDUSTRY}

Pharmaceuticals

APPLICABLE SIC CODES

2676, 2834, 2844, 3841,3842 


\section{The Company}

In March 1995, Lockheed and Martin Marietta merged to form the Lockheed Martin Corporation.

Lockheed Martin is a Fortune 25 company, headquartered in Bethesda, Maryland. It is the largest

defense contractor in the world and the largest aerospace company in the United States. Lockheed

Martin has annual sales of approximately $\$ 23$ billion, employing more than 165,000 people.

The company has core businesses in aircraft, electronics, energy, environment, information and technology services, materials, satellites, and space and launch systems.

LOCATION

Bethesda, Maryland

INDUSTRY

Aerospace, Defense

APPLICABLE SIC CODES

$3577,3699,3721,3728,3761$, $4581,4899,7376,8731,8741$

(This is a representative list of the type of work done at Lockheed Martin, but is not meant to be comprehensive.)

\section{Pledge Highlights}

Lockheed Martin joined the Climate Wise program in May 1994. The company has already realized significant energy and cost savings from its Climate Wise Action Plan. In 1995, Lockheed Martin:

- Consolidated operations, which resulted in the shutdown of 1200 tons of HVAC systems for 8 to 10 hours a day and on weekends

- Began a campaign to shut off lights in offices and common spaces when these areas are not in use

- Installed four energy-efficient chillers, saving $\$ 9,300$ each year

- Shut down an outdoor substation transformer, saving $\$ 9,900$ each year

- Tuned up a boiler, increasing efficiency by $4 \%$

- Implemented a compressed air leak program to reduce air losses and a steam leak program to reduce steam losses.
The company also plans to:

- Install a programmable lighting controller, which will increase energy savings

- Shut down seven substation transformers, saving $\$ 4,400$ annually

- Install a 300-ton chiller, saving $\$ 2,700$ annually

- Install a 50-horsepower AC variablespeed drive for a boiler fan, with a projected annual savings of $\$ 2,600$ to $\$ 5,200$

- Consolidate buildings to reduce active square footage and energy consumption.

To create an intrinsic energy conservation value within the company and increase employees' energy awareness, Lockheed Martin formed a task force to identify and transfer energy efficiency best practices. 


\section{Majestic Metals, Inc.}

\section{The Company}

Majestic Metals, Inc., manufactures precision sheet metal used primarily by the medical and electronic industries. Typical operations include metal shearing, punching, forming, welding, painting, and applying graphics. The company employs approximately 100 people.

\section{Pledge Highlights}

When Majestic Metals joined Climate Wise in February 1995, it was already undertaking several activities to reduce its greenhouse gas emissions. For example, Majestic Metals switched to water-borne or powdercoat products instead of solvent-based products in $97 \%$ of the materials used for operations. In addition, the company has eliminated chlorofluorocarbons from its products and processes, and recycles all cardboard, office paper, metal scrap, and sanding fines. With the assistance of Climate Wise, Majestic Metals pledges to actively pursue pollution prevention opportunities that are ecologically sound and economically feasible.
The company plans to:

- Replace all shop lighting with energyefficient equipment by 1999

- Replace an additional $20 \%$ of its wood pallets with those made of recyclable plastic

- Enhance insulation of heated processing tanks and large shipping doors

- Develop a closed-loop rinse system in the metal prepaint processing area in conjunction with Colorado State University's Industrial Assessment Center, sponsored by DOE.
LOCATION

Denver, Colorado

INDUSTRY

Metals

APPLICABLE SIC CODE 3400 
Climate Wise Partners

Ọvad/Graphics

\section{The Company}

Quad/Graphics is one of the largest privately held printing companies in North America. It serves the magazine, catalog, free-standing insert, direct mail, and commercial products markets.

It is an employee-owned company of about 8500 people nationwide, with annual sales in excess of $\$ 800$ million in 1994.

\section{LOCATION}

Pewaukee, Wisconsin

INDUSTRY

Printing

APPLICABLE SIC CODE 2700

\section{Pledge Highlights}

In April 1994, Quad/Graphics accepted the Climate Wise challenge to reduce greenhouse gas emissions. The company is strongly committed to making the best possible use of all resources. Its goal is to maintain an ongoing $3 \%$ annual reduction in energy use per unit of production. Quad conserves energy by:

- Reducing the number of employee trips to and from work by implementing longer shifts

- Converting fleets to alternative fuel vehicles
- Implementing process changes to conserve energy, such as a solvent recovery system that will reduce ink and solvent use by $50 \%$ and save 2.3 trillion Btu of energy by 2010 , lower temperatures in the ink drying ovens, and heat recovery in water-cooled mechanical systems

- Participating in EPA's Green Lights program

- Increasing carbon sequestration by planting and maintaining a tree farm

- Establishing an energy management bureau. 


\section{Weuerhaeuser Companı}

\section{The Company}

Weyerhaeuser Company is one of the three largest forest products firms in North America. The company grows and harvests timber, and it manufactures, distributes, and sells forest products, including a diverse range of paper products. Weyerhaeuser, employing about 36,000 people, is also involved in real estate development, construction, and financial services. The company owns approximately 5.5 million acres of commercial forestland in the United States.

\section{Pledge Highlights}

In April 1994, Weyerhaeuser joined Climate Wise to help demonstrate how industry can take steps to voluntarily reduce greenhouse gas emissions. The company pledges to:

- Explore ways to reduce concentrations of $\mathrm{CO}_{2}$ in the atmosphere through the management and maintenance of forestland

- Advance minimum impact mill techniques, including the use of recycling in paper manufacturing, to reduce wastewater and save energy

- Examine the use of waste plant material from area farms to replace trees in papermaking.

Weyerhaeuser's environmental policy guides the development and implementation of the company's waste minimization and emissions reduction actions, stating that the company will "conserve energy and natural

LOCATION

Tacoma, Washington

INDUSTRY

Forest and Paper Products

APPLICABLE SIC CODE

2621 


\section{Industrial Case Studies}

This section provides 30 case studies explaining how various industrial companies are improving energy efficiency and reducing pollution. Information was obtained from a variety of sources, such as trade associations, state energy and natural resource departments, the companies in cooperation with OIT, the Industrial Assessment Center (IAC) Program of OIT, and others. The source of information for each case study is clearly defined for the reader. Some case studies identify the company by name, whereas others identify the IAC. The IACs provide confidentiality to all companies participating in their assessments. Therefore, these case studies do not identify the companies by name, but display the name of the IAC that conducted the assessment.

IACs, located in universities throughout the United States, conduct industrial assessments for small- and medium-sized manufacturers at no cost to the manufacturer. These assessments present opportunities for productivity improvements, waste reduction, and energy savings. On average, recommendations from each industrial assessment yield the opportunity for $\$ 55,000$ in annual cost savings and an annual energy savings of 4 billion Btu. By the end of 1994, IACs had conducted more than 5000 assessments and participating manufacturers had cumulatively saved $\$ 517$ million and 94 trillion Btu of energy. By reducing energy consumption, IACs also have contributed to decreasing greenhouse gas emissions by 220,460 tons of carbon equivalent. The IAC case studies demonstrate the wide range of energy efficiency opportunities recommended by IACs across the country and the results companies are achieving from implementing the recommendations made in an audit. (See the Appendix for more information on the IACs.)

The case studies in this section are organized by their Standard Industrial Classifications (SICs). The SIC code system was developed by the U.S. Government to define and analyze industry structure. The SIC classifies companies by the type of activity in which they are engaged. Because most companies are engaged in many different activities, it is common for a company to fall under several SIC codes.
The case studies in this report are listed under the SIC code pertaining to the company's primary activity. Other applicable SIC codes are identified whenever possible.

SIC codes are used by the U.S. Government, state agencies, trade associations, and private research organizations for a variety of purposes. At the Department of Energy, OIT focuses on seven industries that are the country's most energy- and waste-intensive industries to help them attain improved competitiveness and efficiency into the next century. These industries are aluminum (SIC 33), chemicals (SIC 28), forest products (SIC 24, 26), glass (SIC 32), metal casting (SIC 33), petroleum refining (SIC 29), and steel (SIC 33).

The 30 case studies presented on the following pages cover 11 SIC codes: food and kindred products; textile mill products; lumber and wood products; paper and allied products; printing, publishing, and allied industries; chemicals and allied products; rubber and miscellaneous plastic products; primary metal industries; fabricated metal products; industrial and commercial machinery and computer equipment; and wholesale trade. 


\section{Hefrigeration Retrofil Significanliy Reduces Energy Costs}

\section{TECHNOLOGY}

Ammonia refrigeration

system with

automated controls

PARTNERS

Boston Edison, Massachusetts Division of Energy Resources

COST SAVINGS

$\$ 455,000$ annually, payback of 1 year

\section{ENERGY SAVINGS}

6 million $\mathrm{kWh}$ annually

\section{ENVIRONMENTAL BENEFITS}

$\mathrm{CO}_{2}$ emissions reduction of 2500 tons annually

\section{ADDITIONAL BENEFITS}

Increased productivity by $10 \%$, improved employee morale, safer work environment from improved lighting

\section{The Challenge}

Production costs at the Kraft General Foods plant in Framingham, Massachusetts, were not competitive with those of other manufacturing facilities in the division, and increased electricity costs had been causing budget problems. Most of the electricity at the plant was consumed by the plant's refrigeration system. In 1991, Kraft replaced its 1700-ton freon refrigeration system with a 2000-ton ammonia system. As a result, the company saved money on electricity bills and increased its operational efficiency.

\section{The Company}

At the time of project implementation, the Framingham plant was owned by Kraft General Foods Corporation, the largest ice cream and frozen dessert manufacturer in the United States. In 1993, Good Humor, part of Unilever, bought the Framingham plant from Kraft. The Framingham plant produces approximately 20 million gallons of ice cream each year and employs as many as 250 people during peak times.

\section{The Approach}

Plant Operations Manager Joe Crowley and his staff had been investigating options to reduce electricity consumption. One option was cogeneration, but it was not cost effective. Then in 1990, the company embarked on a program with the local utility, Boston Edison. The Framingham plant was the first participant in the Large Commercial/Industrial Retrofit Program of Boston Edison's Energy Efficiency Partnership. The Massachusetts Division of Energy Resources' low-cost energy audit of the plant was instrumental in initiating the program. The retrofit program provides incentive payments to companies based on verified savings from energy efficiency retrofits.

At first, division managers were skeptical about the project and asked Boston Edison to prepare a presentation on the retrofit program. After learning that it was a winwin situation for Kraft and Boston Edison, the Kraft division president granted final approval. After obtaining approval, plant managers still had to address employees' concerns, because the project overhauled familiar equipment. Kraft gained the employees' cooperation by including operating personnel and refrigeration and electrical engineers on the design team.

\section{Project Description}

The plant's 1700-ton freon refrigeration system was replaced by a 2000-ton ammonia system. The plant also installed central computer systems to monitor electrical consumption around the clock and control refrigeration components for optimal energy efficiency. The ammonia system accommodates three different temperature requirements for the ice-cream-making process.

Kraft also replaced the air-handling equipment in the ice cream hardener and freezer. The original 12 air handlers were electrically defrosted and drew about $60 \mathrm{~kW}$. These were replaced with two 80-ton and one 75-ton hot gas defrost units. The new defrost system runs four times a week for 15-minute periods. In comparison, the previous electric defrost units ran four times a day for 120-minute periods.

In addition, the project involved installing high-efficiency motors for homogenizers and pasteurizers and a new lighting system.

Although this measure was not part of the Energy Efficiency Partnership retrofit, Kraft also installed a heat recovery system to reduce its use of fossil fuels. The system uses heat generated by the ammonia compressors to heat water for cleaning. 


\section{Installation and Operation}

To help with the installation, Kraft hired local contractor Stahlman Engineering from New London, New Hampshire, to work with in-house engineers and project specialists on the retrofit. Reco Engineering assembled the ammonia refrigeration system. Construction began in September 1990 and was completed 6 months later. The design team minimized production downtime by scheduling the changeover during the slowest production period.

Kraft spent \$3.6 million to implement the project. Of this sum, $\$ 2.5$ million was spent on the ammonia refrigeration system with computer controls and sensors, another $\$ 1$ million was spent on the air-handling system, and $\$ 150,000$ covered the cost of installing high-efficiency motors and lighting. The heat-recovery system cost the company an additional $\$ 250,000$.

\section{Energy Savings}

Verification of energy savings began in June 1991. Two years later, actual refrigeration energy savings were more than 8 million kWh, exceeding the estimated energy savings by $118 \%$. The air-handling system also reduced electrical consumption by more than 3 million $\mathrm{kWh}$ over 2 years. The motors and lighting retrofit saved another 470,000 kWh. Total savings from June 1991 through May 1993 amounted to 12 million $\mathrm{kWh}$, exceeding estimates by $112 \%$.

Since 1988, the electricity consumed in making each gallon of ice cream has decreased by $25 \%$, and electric costs have decreased by $\$ 0.02$ a gallon to $\$ 0.055$.

\section{Environmental Benefits}

The annual savings of more than 6 million $\mathrm{kWh}$ of electricity and 100,000 gallons of $\mathrm{No} .2$ fuel oil has reduced annual $\mathrm{CO}_{2}$ emissions by 2500 tons.

\section{Economic Benefits}

Kraft realized a $100 \%$ return on investment with the incentive payments. Of Kraft's $\$ 3.6$ million investment over 24 months, all except $\$ 345,000$ was paid back within the first year of operation. The company now saves $33 \%$ ( $\$ 455,000)$ from its $\$ 1.4$ million annual electrical bill.

\section{Impact on Company, Community, and Industry}

The retrofit project and Kraft General Foods won national recognition as the recipient of the Association of Energy Engineers' Project Award for 1992. Kraft also gained the support of neighboring communities by reducing air emissions and reducing water use by 1 million gallons annually.

The retrofit project turned the oncefragile Framingham plant into one of Kraft's most competitive and efficient facilities. Productivity increased by $10 \%$ and, consequently, employee morale improved. Employees also enjoy a safer working environment as a result of having better lighting. Two plant engineers involved in the project won leadership awards from Kraft.

Employees now have a greater sensitivity to the environment. Since the retrofit, they have completed other environmentally friendly projects, such as substituting ozone for chlorine in their cooling-tower water.

This successful retrofit project is applicable to all companies with significant refrigeration and air-handling operations.
WHO USES IT?

Food processors

Refrigeration and air-handling operations

APPLICABLE SIC CODE 2000

CONTACT

Joseph Crowley

Good Humor Unilever

(508) 620-4300

John Donoghue

Boston Edison

(617) 424-2064

SOURCE

Good Humor Unilever,

Boston Edison, and

American Council for an Energy-Efficient Economy 


\section{Energu-Efficient Boiler Reduces Energu Consumption and Air Emissions}

TECHNOLOGY

Boiler

BENEFITS

$40 \%$ reduction in natural gas consumption, reduced air emissions, improved worker safety

APPLICABLE SIC CODE 2015

SOURCE OF CASE STUDY

Getting in Gear,

Alliance to Save Energy, Washington, D.C., 1995.

\section{The Challenge}

Processing poultry requires water heated to between $120^{\circ} \mathrm{F}$ and $130^{\circ} \mathrm{F}$. Mar-Jac, Inc., used three natural-gas-fired boilers to supply steam to its heat exchangers, which heated the water. However, the boilers' low efficiency resulted in high energy costs, and maintenance was difficult and expensive.

The company was looking for a way to provide the hot water it needed but at less cost and with more reliability.

\section{The Company}

Mar-Jac, Inc., is a poultry processor in Gainesville, Georgia. The company employs about 550 people.

\section{The Approach}

Mar-Jac is always looking for new ways to improve its facilities. In the mid-1970s, the company installed-with help from the Georgia Institute of Technology—a scalder overflow heat-recovery system. In addition, the plant engineer recently increased the facility's power factor by $10 \%$ to $15 \%$ by installing capacitors on all electric motors with more than 20 horsepower.

When the plant manager read a trade journal article about a new type of directfired gas water heater, he visited other plants that used the system to see the equipment in operation. The plant manager agreed that this was a simpler, less expensive way of producing hot water.

\section{Project Description}

Mar-Jac replaced its three steam boilers with two new water heaters capable of supplying water at $180^{\circ} \mathrm{F}$. Process improvement and energy savings were both key factors in the board's decision to switch to the new water-heating system. The new system cost $\$ 210,000$.

\section{Energy Savings}

The project reduced Mar-Jac's natural gas consumption by $40 \%$, which resulted in a payback period of less than 3 years.

\section{Environmental Benefits}

These new water heaters produce fewer emissions than did the company's previous boilers.

\section{Additional Benefits}

The new system decreased maintenance costs and improved safety by reducing the possibility of blowing a boiler. 


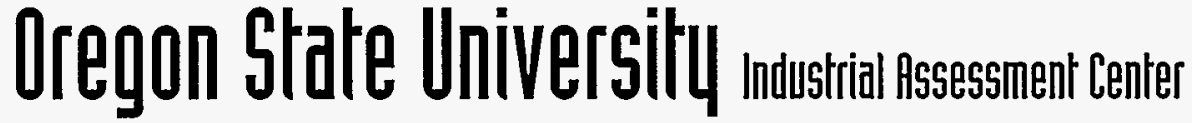

\section{The Challenge}

During a 12-month period from May 1993

to May 1994, a dairy product company consumed 15,920 million Btu of energy at a cost of $\$ 122,770$. Electricity accounted for the majority of the company's energy cost and usage (10,620 million Btu or $\$ 98,913)$; natural gas accounted for the remainder. After the Oregon State University IAC's assessment in February 1994, the dairy company implemented energy efficiency measures that are saving it $\$ 17,764$ per year.

\section{The Company}

The plant produces a variety of fluid dairy products, including milk, chocolate milk, whipping cream, and fruit-flavored drinks. In addition, the plant manufactures its own plastic bottles and caps. It is operated by 54 employees who produce 65 million pounds of products for annual sales of $\$ 15$ million. Natural gas is used by the boilers to provide process heat for pasteurizing and cooking and to provide hot cleaning water. Compressors operate the ammonia refrigeration systems used for process cooling and product cold storage. Other uses of electricity include air compression, blow molding (plastic bottles), injection molding (bottle caps), and lighting.

\section{IAC Recommendations}

- Raising the compressor suction temperature and lowering the compressor discharge pressure would reduce compressor work, saving nearly 1500 million Btu per year and $\$ 12,000$ annually. The IAC recommended that a refrigeration engineer or contractor be consulted before making the adjustments.
- Recovering air compressor waste heat to preheat cleaning water would reduce boiler natural gas usage annually by 1900 million Btu and save $\$ 8,500$ per year.

- Installing fixed capacitance to raise the power factor above 0.95 would save about $\$ 4,100$ per year in penalty charges. (The plant is charged a penalty if the power factor in a billing period is less than 0.95 .)

- Insulating steam lines and replacing standard motors, as they burn out, with high-efficiency motors would save the company $\$ 2,800$ per year.

\section{Energy Savings}

The plant now saves about 3200 million Btu per year by implementing the IAC's recommendations.

\section{Economic Benefits}

The plant saves $\$ 8,500$ per year in natural gas costs by using air compressor waste heat to preheat cleaning water via an air-to-water heat exchanger. The measure was implemented with an initial cost of about $\$ 9,000$. Operational changes to the refrigeration system by in-house personnel result in annual cost savings of $\$ 6,500$. Additionally, replacing standard motors with highefficiency motors and insulating 120 feet of steam line save $\$ 2,800$ per year.

In total, the plant saves nearly $\$ 17,800$ annually. The average payback for these measures is about 8 months.
COMPANY

Manufacturer of fluid dairy products

AUDIT DATE

February 1994

COST SAVINGS

$\$ 17,764$ annually

ENERGY SAVINGS

3229 million Btu annually 


\section{South Dathota State Universitપ Industrial lssesssnent Center}

COMPANY

Manufacturer of

frozen bakery products

AUDIT DATE

August 1994

COST SAVINGS

$\$ 35,300$ annually

ENERGY SAVINGS

1854 million Btu annually

\section{The Challenge}

From May 1993 to May 1994, a frozen-food manufacturer used 18,000 million Btu of energy at a cost of $\$ 193,215$. Electricity accounted for most of the energy costs ( $\$ 142,184$ or 7561 million Btu). Natural gas consumption accounted for the rest. After the South Dakota State University IAC's assessment, the manufacturer implemented several measures that save the company about $\$ 35,300$ annually.

\section{The Company}

The plant manufactures frozen pot pies and filled pasta products. The plant is operated by 100 employees who produce 8 million pounds of product for annual sales of $\$ 2.3$ million. Electricity is primarily used for lighting, air conditioning, baking, process cooling, compressing plant air, and conveying materials. Natural gas fuels a boiler and forced-air heating units.

\section{IAC Recommendations}

- Recovering waste heat from the baking oven exhaust to preheat air for space heating would reduce the company's natural gas usage by about 600,000 cubic feet per year, with an annual cost savings of $\$ 3,000$. To achieve this cost savings, an air-to-air, heat-recovery unit and oven exhaust vent modifications would be required.

- Insulating the baking ovens and boiler would reduce energy usage by nearly 600 million Btu per year and save about $\$ 11,000$ annually.

- Retrofitting the electric baking ovens with natural gas burners would result in a net increase in annual energy usage of 310 million Btu, but the lower unit cost of natural gas would lead to a savings of about $\$ 15,700$ per year.
- Replacing the standard motors, as they burn out, with high-efficiency motors would save $\$ 560$ annually.

- Taking advantage of the region's cool weather by ducting outside air to the compressor intakes would save approximately $\$ 300$ annually. Outside air is (on average) cooler than plant air and therefore more dense, so it requires less energy to compress.

Implementing lighting system improvements would save 1200 million Btu per year and $\$ 23,500$ annually.

\section{Energy Savings}

By following several of the IAC's recommendations, this company is saving 1854 million Btu annually.

\section{Economic Benefits}

The company realizes annual cost savings of about $\$ 23,500$ through lighting efficiency improvements. The manufacturer used rebates available from the local utility to achieve a payback of less than 8 months. Insulating the baking ovens saves an additional $\$ 10,900$ annually. By ducting cooler outside air to the compressor intakes and replacing standard motors with highefficiency motors, the company also saves $\$ 900$ annually.

In total, the company achieves annual cost savings of $\$ 35,300$. The measures cost about $\$ 17,300$ to implement, resulting in a simple payback of 6 months. 


\section{The Challenge}

Tillamook Country Smoker had two problems: high energy bills and not enough hot water. To meet Food and Drug Ädministration requirements, the company needs water for cleanup purposes to be $180^{\circ} \mathrm{F}$. However, the plant's 100-gallon gas water heater could not keep up with the demand, and it cost the company a lot to heat that much water.

Tillamook Country Smoker's problems were solved with the help of a state tax credit from the Oregon Department of Energy (ODOE). This enabled the company to purchase a heat-recovery system that provides all the hot water it needs at a lower cost.

\section{The Company}

Tillamook Country Smoker in Bay City, Oregon, makes about 25,000 pounds of jerky and 50,000 pounds of pepperoni each week. The plant processes food 12 hours a day, 5 days a week. Cleanup crews follow the production shift for another 8 hours each day.

\section{Project Description}

"We were spending a lot on hot water every day," said Dick Crossley, part owner of Tillamook Country Smoker. "We had to shut down a few times because we ran out of water."

To avoid the expense of a boiler, Crossley and his partners turned to a heat-recovery system. The system captures waste heat from the freezer and cooler condensers, which operate continuously, and uses it to preheat water for the water heater.

The system also recovers heat from the rooms where meat is dried. Reclaimed heat from four drying rooms is used to preheat water before it goes into storage tanks. Now, there is more than enough hot water for cleanup. "It's a great system," said Crossley. "Now we have more hot water than we need. It's clean and it's easy."

Total cost for the system was about $\$ 50,000$. The Tillamook Country Smoker received a 35\% Business Energy Tax Credit, equal to about $\$ 16,714$, to help offset that cost.

\section{Energy Savings}

The heat-recovery system is saving the company about $\$ 72,000$ each year in energy costs.

\section{Additional Benefits}

The money the company saves on energy costs is put toward other uses, including expansion. The company added five more drying rooms and hired more employees. The plant, which started with 6 employees, now has more than 80 .

For more information, contact the Oregon Department of Energy at 1-800-221-8035. Any Oregon business that installs energysaving or energy-producing equipment may apply for the credit. To qualify, ODOE must approve your system for a tax credit before it is bought and installed.

\section{Heak-Hecovery Sustem Cuts Energu Costs}

TECHNOLOGY

Heat-recovery system

\section{BENEFITS}

$\$ 72,000$ savings on energy costs

APPLICABLE SIC CODE 2000

SOURCE OF CASE STUDY

Oregon Department

of Energy, Business Focus, $330-19,10-86 / 500$. 


\section{University of Missouri-Rolla manstrial lssessment enter}

COMPANY

Processor of denim jeans

AUDIT DATE

July 1994

COST SAVINGS

$\$ 113,584$ annually

ENERGY SAVINGS

35,892 million Btu annually

\section{The Challenge}

From May 1993 to May 1994, a company spent almost $\$ 800,000$ on energy. Natural gas accounted for most of the energy cost and usage (about 201,000 million Btu or $\$ 619,000$ ). The remaining sum was spent on electricity. After the University of Missouri-Rolla IAC's assessment in July 1994, the company implemented energy efficiency measures and is saving $\$ 113,584$ per year.

\section{The Company}

The plant employs 175 people and is responsible for washing (including acid and stone washing) about 13 million pairs of denim jeans per year for annual sales of about $\$ 37$ million. A boiler and several dryers and water heaters are the major process users of natural gas. The major electrical process equipment are 2 air compressors and 36 industrial-grade washers.

\section{IAC Recommendations}

- Covering the wash water storage pits to reduce heat losses would save $\$ 68,600$ per year. Reducing the pit heat losses would increase the amount of preheating and lower the natural gas usage of the water heaters by about 22,400 thousand cubic feet annually.

- Replacing an oversized natural gas boiler with an electric boiler that has an output rating more closely matched to the required steam load would result in annual savings of both 10,400 million Btu and about $\$ 28,000$.

- Installing electronic ballasts and reducedwattage fluorescent lamps would save this plant nearly $\$ 1,200$ per year.
- Replacing standard motors with highefficiency motors as the original equipment burns out and replacing standard V-belts with notched V-belts would annually save both 600 million Btu and $\$ 6,300$.

- Ducting cooler outside air to the intakes reduces the energy required to compress air. Reducing the compressor discharge pressure and using synthetic lubricants would also reduce the energy consumed by the compressors. These measures would reduce electrical consumption by about 420 million Btu per year and save approximately $\$ 4,400$ per year.

\section{Energy Savings}

The recommendations implemented by the company have saved nearly 36,000 million Btu of energy per year.

\section{Economic Benefits}

This manufacturer is saving nearly $\$ 113,600$ annually as a result of the IAC's recommendations. The total implementation cost was only $\$ 13,300$, resulting in about a 2-month payback period.

The plant saves $\$ 75,000$ per year (more than indicated by the IAC) by covering wash water storage pits to reduce heat losses. A less expensive cover than recommended was used, which resulted in a payback of less than 1 month. Using an electric boiler already at the plant, but not previously in use, saves an additional $\$ 28,000$ per year. Other recommendations-including motor system improvements, air compressor system modifications, and lighting efficiency improvements-save about $\$ 10,600$ annually. 
Industrial Case Studies continue on following page 


\section{Variable-speed Drive Saves Energu and Moneu}

TECHNOLOGY

Variable-speed AC drive on induced draft

\section{BENEFITS}

Cost savings of $\$ 17,888$ per year, energy savings of more than $830,000 \mathrm{kWh}$ annually, reduced exhaust stack particulate emissions

APPLICABLE SIC CODES

2400,2600

\section{SOURCE OF CASE STUDY}

Bonneville Power Administration, Energy Savings Plan Case Studies, DOE/BP-1466, October 1990.

\section{The Challenge}

SDS Lumber Company uses an induced $\mathrm{draft}$ fan to reduce the air pressure inside its furnace. By continuously running at a constant speed, no matter what the load of the furnace was, the fan was wasting energy and thus costing the company money. SDS Lumber decided to increase the energy efficiency of its induced draft fan by installing a variable-speed drive.

\section{The Approach}

SDS Lumber estimated that varying the motor speed of its induced draft fan, rather than altering the damper position, would result in substantial energy savings.

However, the company was not sure enough to invest engineering time and money into making the change. The Energy Savings Plan sponsored by Bonneville Power Administration provided the opportunity to investigate the proposed system change to a variable-speed AC drive (known as VSD) on the fan motor. "The Energy Savings Plan was what we needed," says SDS Lumber Company Electrical Supervisor Ron Schultz. "We would have the technical and monetary assistance from Bonneville Power Administration and a better, more efficient system in the end."

The Energy Savings Plan makes cash investments in technology and improvements that increase the energy efficiency of an industry's process or facility and is sponsored by the region's electric utilities and Bonneville Power Administration.

\section{Project Description}

The Gorge Energy Division of SDS Lumber Company supplies steam for the company's plywood and lumber manufacturing processes and for a cogeneration facility. Steam is produced by burning wood waste products in an induced draft furnace. As steam demand from SDS Lumber Company's manufacturing processes increases, the need for more fuel also increases. The resulting increased heat produces expanding gases, known as induced draft air, which need to be drawn out of the furnace to maintain pressure within certain tolerance limits. SDS Lumber uses a 400-horsepower induced draft fan, or ID fan, on the output side of the furnace to draw out the excess air and reduce pressure.

Usually the fan and motor are large enough to remove the maximum amount of expanded gases, plus a safety margin. For loads less than maximum, the output side of the fan has a set of damper vanes, which are opened or closed to regulate airflow. While the damper vanes reduce airflow through the firebox, the energy required to operate the fan remains the same. This system is inefficient because the motor runs at full-rated output speed no matter what the load.

The VSD system reduces energy requirements because it maintains a stable airflow in the furnace by altering the frequency, voltage, and current to the fan motor.

\section{Installation and Operation}

When the VSD was installed, SDS Lumber decided to leave the existing damper vanes in place for two reasons: (1) to provide a backup if the VSD failed, and (2) to fine-tune pressure changes within the system because the rotating mass of the fan is so large that the VSD may not be able to respond fast enough to minor fluctuations in load. 
The project cost $\$ 45,925$ to implement. The Energy Savings Plan awarded an incentive to the company for $80 \%$ of the project cost.

\section{Energy Savings}

Initial energy savings calculations estimated that SDS Lumber could save $688,858 \mathrm{kWh}$ each year $(\$ 14,810)$ with a relatively small investment to install the VSD system. SDS Lumber decided to proceed with the project. It conducted pre-installation monitoring of the dampened system to establish a baseline for post-installation evaluation. The tests showed that the dampened system was more inefficient than initially estimated.

Post-installation tests showed an energy savings of $831,996 \mathrm{kWh}$ per year, or $\$ 17,888$, which was greater than originally calculated. A fairly constant airflow in the firebox shows that the VSD regulates the furnace pressure better than the old dampened system.

\section{Environmental Benefits}

An added benefit that SDS Lumber hadn't considered was a reduction in the exhaust stack particulate emissions.

\section{Economic Benefits}

SDS Lumber concluded that VSDs used for certain applications, such as fans and pumps, can result in significant energy savings. The payback in both energy savings and maintenance is substantial. SDS

Lumber saves about $\$ 18,000$ per year with this one VSD. 


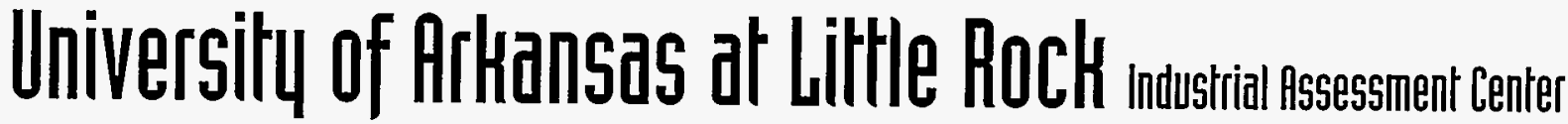

\section{COMPANY}

Producer of preserved railroad cross ties

AUDIT DATE

May 1994

COST SAVINGS

$\$ 145,000$ annually

ENERGY SAVINGS

28,880 million Btu annually

\section{The Challenge}

During a 12-month period ending in May 1994, a railroad tie manufacturer used about 111,000 million Btu of energy at a cost of $\$ 548,290$. Natural gas accounted for 99,900 million Btu and cost the company $\$ 272,440$. The remaining Btu were for electricity. After implementing all recommendations made by the University of Arkansas at Little Rock IAC, the plant is saving $\$ 145,000$ annually.

\section{The Company}

The plant, which has 85 employees, produces 5 million cubic feet of preserved railroad cross ties annually for sales of $\$ 27$ million. The major energy-consuming equipment for this process includes a 150horsepower air compressor, 40- and 75horsepower pumps, various motors, three boilers, and heated creosote treatment and supply/storage tanks. The raw material consists of cut oak, gum, and pine ties, which are air dried for 10 to 12 months until reaching about $45 \%$ moisture. The ties are drilled, stamped, and placed on a tram, which is then placed in a tank. The tank is flooded with creosote, pressurized, and heated for a total of 7 hours. The creosote is drained from the tanks, and the ties are then stacked and stored to await shipping.

\section{IAC Recommendations}

- Improving the steam system at the plant could save 26,000 million Btu of natural gas per year and $\$ 71,000$ annually. Repairing the leaks in the live steam lines and condensate return lines would reduce the energy usage for heating makeup water, leading to reduced water purchases and treatment costs. Insulating the creosote and steam supply lines would reduce heat losses and associated costs. Currently, an uninsulated, leaky steam line supplies the diesel washdown station. If the existing portable washdown unit is used, this steam line could be disconnected and save 1480 million Btu of natural gas per year and $\$ 4,000$ annually.

- Reducing the lighting in areas that are currently over-illuminated and replacing existing standard lamps with highefficiency lamps would save 145 million Btu per year and $\$ 3,500$ annually.

- Installing capacitors to improve the plant's power factor would result in annual savings of $\$ 52,700$. The plant is charged by the local utility when its power factor falls below unity.

- Conducting monthly tests on the 75horsepower fire pump during off-peak hours would eliminate contribution to the peak demand during the billing period, saving $\$ 7,700$ per year.

- Replacing standard V-belt drives with segmented belts would reduce the internal friction in the belts, resulting in a decrease in required motor horsepower. This action would save 100 million Btu per year and $\$ 2,400$ annually.

- Installing high-efficiency motors to replace standard efficiency motors currently used at this facility would save 140 million Btu annually and $\$ 3,300$ per year. In addition, insulating the creosote storage/supply tanks to reduce heat losses from tank surfaces would result in annual savings of both 2600 million Btu of natural gas and $\$ 7,000$. 


\section{Energy Savings}

The manufacturer chose to implement all of the recommendations suggested by the IAC. As a result, the company saves 28,880 million Btu annually. Repairing steam leaks, insulating steam lines, and disconnecting an unused steam line result in annual savings of 26,000 million Btu of natural gas. Installing high-efficiency lighting and eliminating unneeded lighting conserve 145 million Btu of electricity per year. The remaining measures-replacing standard V-belts, installing high-efficiency motors, and insulating process tanks-save 2700 million Btu per year.

\section{Economic Benefits}

By implementing the IAC's recommendations, the company saves $\$ 145,000$ per year. The capital cost of these improvements was approximately $\$ 61,000$, resulting in a payback of 5 months.

Repairing and insulating steam lines results in annual savings of $\$ 71,000$. Installing capacitors and shifting the monthly test of the fire pump to off-peak hours save more than $\$ 60,000$ per year in demand charges. Upgrading to high-efficiency lighting and eliminating unnecessary lighting saves $\$ 3,500$ annually. The remaining measures save $\$ 10,000$ per year. 


\section{Steam Reduction Project Saves Energu and Reduces Emissions}

\section{TECHNOLOGY}

Turnkey heat

recovery system

PARTNERS

Minnesota Power

COST SAVINGS

$\$ 1.8$ million annually

ENERGY SAVINGS

2.3 million $\mathrm{kWh}$ annually

\section{ENVIRONMENTAL. BENEFITS}

$\mathrm{CO}_{2}$ emissions reduction of 37,000 tons annually

\section{ADDITIONAL BENEFITS}

Improved employee morale, increased company recognition

\section{The Challenge}

Through energy auditing, Blandin Paper Company discovered significant heat losses in gaseous stack emissions from-paper drying and other processes. Temperatures of paper-drying emissions measured $180^{\circ} \mathrm{F}$ with significant heat capacity available. Blandin captured this energy by installing an innovative system that recovers heat from process emissions and reduces steam consumption at the mill.

\section{The Company}

Blandin Paper Company, a subsidiary of Fletcher Challenge Canada Limited, employs about 1100 people at the Pressure Ground Wood Pulp and Light Weight Coated Paper plant in Grand Rapids, Minnesota. Blandin has been making paper at this location since 1902. Annual sales in 1994 were $\$ 297$ million. The company's coated paper is made from kraft pulp and pulp containing approximately $60 \%$ hardwood (aspen) and $40 \%$ softwood (balsam and spruce).

\section{The Approach}

The energy-conscious managers at Blandin are always evaluating new opportunities to reduce energy costs at their plant. As a result, they rose to the challenge presented by Minnesota Power's Industrial Conservation Pilot Program to explore innovative actions to conserve electric power and make industrial processes more energy efficient. A 1994 energy audit pointed out ways Blandin could further benefit its production costs, the environment, and the community, while taking advantage of Minnesota Power's program. The project was funded by Blandin and the Minnesota Power tax, to which Blandin had contributed for several years. The project required the approval of Minnesota Power and the state energy commission.

\section{Project Description}

The objectives of this project were to reduce the steam consumption, fuel use, and emissions at the mill. To achieve these objectives, Blandin installed a heat recovery system built by Valmet-Enerdry. This pressurized ground-wood, heat-recovery system reclaims and heats effluent water for the woodroom. It also heats glycol for make-up air heating and heats white water for the stock going to the company's four paper machines.

Each paper machine already included systems to recover heat from paper machine exhaust. This recovered heat is used to preheat make-up air for the plant. The systems were modified so that heat from vacuum condenser water could also be used to heat wet-end shower water. Blandin also uses split-stage, shower-water heating before and after the make-up air heating on the paper machine exhaust systems to maximize recovery. Blandin installed process measurement devices so operators would be able to monitor and manage the systems to optimize performance.

\section{Installation and Operation}

From January to April 1994, Blandin performed studies and gathered data. After the applications for funding were approved in June 1994, the company began installing the heat-recovery system. The installation process caused some disruptions, since lines not normally closed had to be completely shut down. Installation of the system has been completed on three of the four paper machines. Installation on the remaining machine will be completed in the near future. Blandin's expectations for the project have already been exceeded.

The total project cost was $\$ 2,168,000$. Blandin spent $\$ 89,000$ on studies and data gathering, $\$ 30,000$ on the performance audits, and $\$ 2,049,000$ for installation. Minnesota Power covered $\$ 833,000$ of the project costs. 


\section{Energy Savings}

The heat recovered will produce a net annual electrical savings of 2.3 million $\mathrm{kWh}$, or $\$ 91,000$. The savings result from lower electrical use in the steam production on two of the mill's boilers. Some additional power is used by the new heat-recovery equipment, but the net result is a reduction of $7.3 \mathrm{kWh}$ per ton of product.

The steam-reduction project eliminates the use of 654 million pounds of steam each year in the paper-making process. This change also eliminates more than 740 million cubic feet of natural gas that was used to produce this steam in two of the plant's boilers.

\section{Environmental Benefits}

Stack emissions from two boilers have decreased as a result of the lower fuel usage from reduced steam requirements. Reductions in annual emissions include 14 tons of $\mathrm{CO}, 197$ tons $\mathrm{NO}_{\mathrm{X}}$, and 37,000 tons of $\mathrm{CO}_{2}$.

\section{Economic Benefits}

Total cost savings from this project is estimated to be more than $\$ 1.8$ million per year. This annual savings results from
$\$ 91,000$ in electrical energy savings, $\$ 1,638,000$ in fuel savings, and $\$ 77,000$ in reduced costs for boiler feedwater makeup treatment. The project reduces Blandin's product costs by $\$ 4.20 /$ ton.

\section{Impact on Company, Community, and Industry}

As a result of this project, Blandin won the 1994 award from the American Forest and Paper Association for energy management and innovation. The project also has a positive effect on the community. There has been a slight reduction in exhaust plume, which improves air quality for the surrounding neighborhood.

Because profit sharing is included in employees' compensation, they gain financially from the reduced costs resulting from this project.

Paper mills account for more than $90 \%$ of the energy consumed in the forest products industry. This steam-reduction project offers a solution to paper mills across the country that are seeking ways to reduce energy consumption.
WHO USES IT?

Paper mills

APPLICABLE SIC CODES

2493,2621

CONTACT

Joe Parkinen

Blandin Paper Company

(218) $327-6200$

SOURCE

Blandin Paper Company

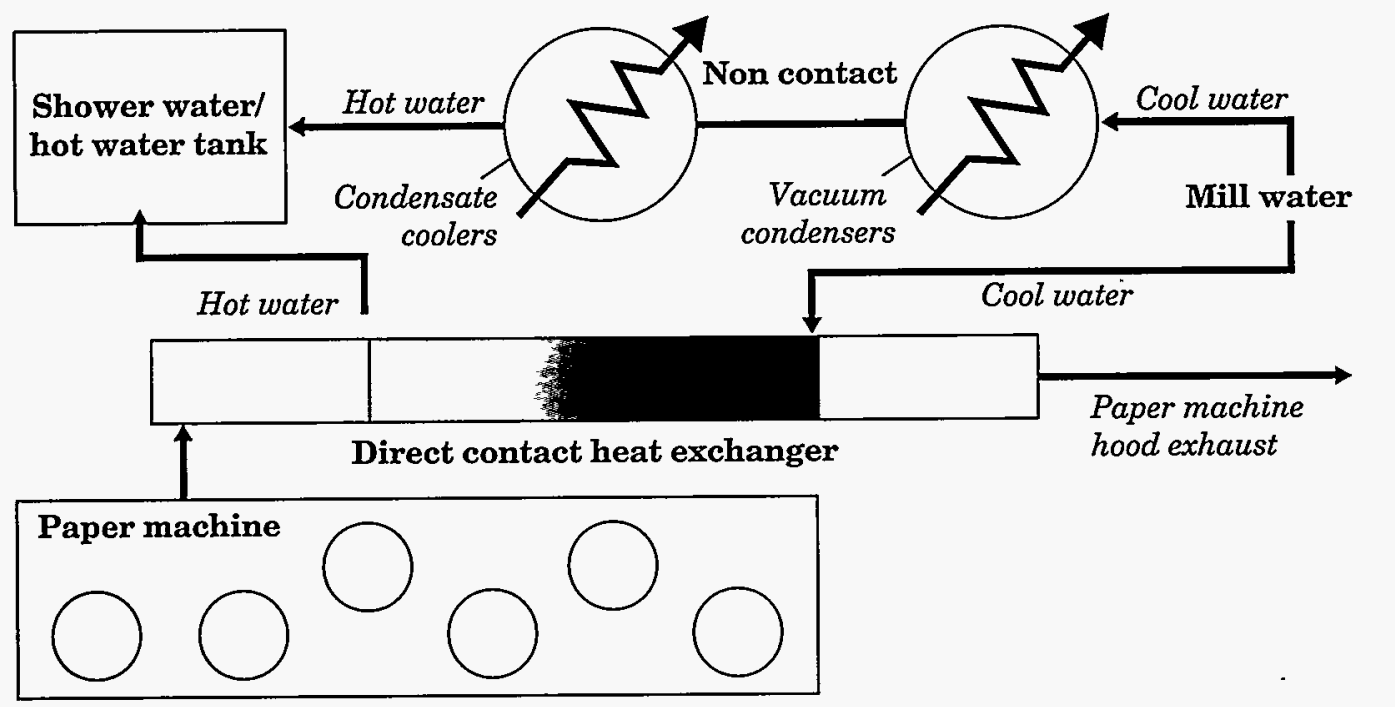




\section{Bowater Incorporited}

Mechanical Vapor

Recompression Heat

Pump Captures

Escaping Steam

TECHNOLOGY

Heat pumps

BENEFITS

$\$ 1$ million annual energy savings, reduced noise level, improved competitiveness

by controlling production costs

APPLICABLE SIC CODES

$2000,2100,2200$,

$2600,2800,2900$

SOURCE OF CASE STUDY

EPRI Pulp and Paper

Office, TechApplication,

Vol. 3, No. 6, 1991

\section{The Challenge}

Every day, low-pressure steam was vented to the atmosphere from Bowater Incorporated's Carolina Division's seven thermomechanical pulping (TMP) refiner lines. The staff at Bowater wondered how the steam could be used to decrease the company's energy cost. Abundant quantities of low-pressure dirty steam were generated in the TMP pulping process. The Bowater TMP utilizes refiners having large counter-rotating disks, each driven by motors as powerful as 8000 horsepower, to macerate wood chips that are injected through the center of the disks. These green wood chips are $50 \%$ water and $50 \%$ fiber. During the process, the water flashes to steam as the fibers are separated, processed, and pumped to paper machines that convert it to newsprint and coated magazine base stock. Today, Bowater employees no longer hear the sound of escaping energy after installing mechanical vapor recompression heat pumps.

\section{The Company}

Bowater Incorporated manufactures market pulp, newsprint, and coated magazine paper at three locations in North America. The mill at the Carolina Division in Columbia, South Carolina, was originally built as a chemical pulp mill in 1959. Since then, it has undergone significant expansion and modernization and is now one of the largest and most modern mills of its type in the world. Originally part of Bowater United Kingdom, Bowater Incorporated became an independent company in 1984 and currently employs about 1250 people at the plant.

\section{The Approach}

When the seven TMP refiner lines were installed at the plant in 1986, Bowater included three reboiler heat exchangers to produce clean steam from the dirty steam. The company planned to use the clean steam at $57 \mathrm{psig}$ in its paper-drying operations. The low-cost recaptured steam would replace a portion of the steam generated from boilers, some of which were often fired by costly oil and natural gas. But the operating temperatures and pressures in the TMP refiners required to produce steam at $57 \mathrm{psig}$ burned and discolored the southern pine wood pulp and reduced quality. Operating the TMPs at lower temperatures and pressures to maintain quality meant the reboilers could only provide steam at $19 \mathrm{psig}$, which was too low to be useful in the paper dryers.

Bowater considered several possibilities, such as thermal vapor recompression, to raise the pressure of the recaptured steam. Bowater determined that using thermal vapor recompression to raise the pressure high enough was not economical.

When the company began looking for a way to improve the use of its low-pressure steam, representatives of Duke Power presented the advantages of industrial heat pump technology. When Bowater learned about a mechanical vapor recompression (MVR) heat pump, it finally had the solution. 


\section{Project Description}

In 1988, Bowater installed two MVR heat pumps to efficiently convert the 19-psig steam at $250^{\circ} \mathrm{F}$ from the reboiler to $57-\mathrm{psig}$ steam at $470^{\circ} \mathrm{F}$ for use in the drying stage of its paper production operations.

Unforeseen problems occurred in the summer of 1989 after 7 months of successful operation when, within 24 hours, the compressors of both MVRs failed. The compressor failures were due to faulty reboiler operation that permitted hot water instead of steam to be fed to the compressors. For a time, the heat pumps lay idle, while potentially valuable steam was again vented to the atmosphere. Because the MVRs' potential for energy savings was so great, Bowater isolated and corrected the problem in the reboilers, rebuilt one of the compressors, and put the MVR back into operation.

Bowater invested $\$ 1.5$ million for the equipment and installation of the heat pump portion of the TMP system and another $\$ 250,000$ for rebuilding one of the heat pumps after it had been damaged. Payback for the system was 1.5 years.

\section{Energy Savings}

The company had projected annual energy savings of $\$ 1$ million, which it achieved from installing the single operating heat pump. This pump generates from $60 \%$ to $90 \%$ of the steam used by the dryers of the company's largest paper-making machine.

\section{Environmental Benefits}

About 200 gallons of turpentine, an important by-product of the TMP process, are recovered daily. This recovered turpentine reduces atmospheric emissions and provides an added source of revenue.

\section{Additional Benefits}

As a result of the MVR operation, Bowater is now able to save 100 gallons of water per minute that had been escaping to the air as steam, saving about $\$ 144$ per day. By controlling the steam vapor once released to the atmosphere, the plant also operates at a lower noise level.

The MVR compressor has a turndown of $50 \%$ to easily adapt to changing amounts of steam from the TMPs and optimize energy usage. The 2000-horsepower compressor uses $30 \mathrm{kWh}$ per thousand pounds of steam produced.

Bowater's MVR heat pump helps control pulp and paper production costs, which contributes to the company's competitive position in the marketplace.

\section{Industrial Relevance}

Mechanical Vapor Recompression units can be used for many different applications, including processing dairy products, fruit juices, pharmaceuticals, wastewater, and chemicals.

For more information, contact the EPRI Pulp and Paper Office, Atlanta, Georgia, at (404) 853-9511. 


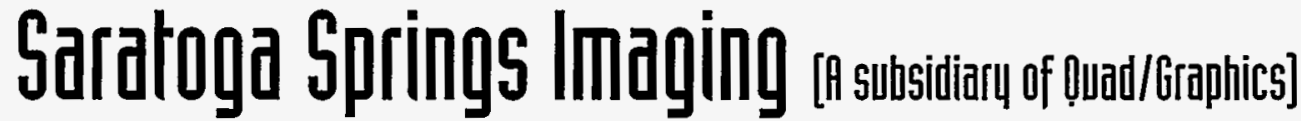

\section{Silver Reclamation Sustem Saves Companu Money and Energy}

\section{TECHNOLOGY}

Silver reclamation and wash system

\section{COST SAVINGS}

More than $\$ 52,000$ annually, payback of less than 1 year

\section{ENERGY SAVINGS}

200 million Btu annually

ENVIRONMENTAL BENEFITS

$\mathrm{CO}_{2}$ emissions reduction of 7 tons annually

\section{The Challenge}

Discharging silver into sewage treatment plants is strictly regulated because of its harmful effects on the bacteria that break down sewage. Silver is a main component of film and is used to burn images onto printing plates. When film is developed, a fixer removes the non-image areas. The used fixer contains silver, which must be recovered. Local regulations for the discharge of silver to the treatment system are 100 times more stringent than U.S. Environmental Protection Agency standards. To meet these local regulations, Saratoga Springs Imaging (SSI), a subsidiary of Quad/Graphics, installed a fixer recycling system that recovers this silver.

\section{The Company}

Quad/Graphics of Pewaukee, Wisconsin, employs about 8500 people nationwide and is the ninth largest printer in the United States by sales volume. New York-based subsidiary SSI employs more than 200 people and is part of a larger Quad/Graphics printing plant with more than 1000 employees. Among its accounts are many of the best-known magazines, including Time, Newsweek, People, Audubon, and National Wildlife.

\section{The Approach}

Quad/Graphics is proactive by implementing practices that are good for business as well as for the environment. The company encourages its employees to find better, more efficient use of resources. Garry Simon, a production manager at SSI, takes this challenge very seriously and works hard to reduce the environmental impacts of his printing facility. In keeping with the company's concern for the environment, he began searching for ways to recover the silver in used fixer. Working with several of its film and plate suppliers, SSI tested a variety of silver reclamation units for effectiveness and ease of use before deciding on the system made by Agfa called Recyfix.

\section{Project Description}

The Recyfix system connects directly to the film processor. Used fixer flows through the system and the silver plates out onto a slightly charged, flexible surface. By removing the plate and flexing it, Production Manager Garry Simon says, "The silver just falls off by the pound." SSI then sells the silver.

The system is also fitted with a charcoal filter that removes any developer solution that gets into the fixer when the films are moved from the developer tank to the fixer tank. The system then adds a rejuvenator to the fixer and returns the fixer to the film processors where it is reused. The closed-loop system prevents any fixer or silver from going down the drain. When the fixer has been reused as much as possible, it is run through an ion-exchange cartridge to further reduce the amount of silver in the wastewater.

In the final stage of the developing process, the film is removed from the fixer tank and rinsed in a water tank to wash off any residue. This residue still contains small traces of silver. Although it is not enough to remove and sell, it still presents a slight environmental hazard. To prevent the rinse water from going down the drain, the water tank is now a closed-loop system. 
Water is slowly injected into the tank as needed for rinsing off the film. Used water from the tank passes through two filters to remove small traces of any fungus or algae that would otherwise contaminate the water tanks. The used water is then run through an ion exchange unit to reduce the silver content before being discharged down the drain. Now, instead of using 1 gallon of water per minute through the wash tray, SSI just uses 7 gallons per day.

\section{Installation and Operation}

The Recyfix system cost $\$ 32,000$ and took about 1 day to install. The system, about 32 square feet in size, had to be plumbed into each processor so that the one central unit could treat all the fixer used at SSI. This system can handle fixer from up to 15 processors.

After the recycling system was installed in 1994, SSI used only $44 \%$ of the fixer it used in 1991. The rejuvenator used to make the fixer reusable is an additional expense, but because less fixer is used, there is still a net cost savings of $31 \%$ each year. Each filter used in the wash water system costs $\$ 17.50$, but this expense is offset by the weekly savings in water bills.

\section{Energy Savings}

Instead of heating 1440 gallons each day to $90^{\circ} \mathrm{F}$ to wash the prints, SSI now has to heat just 7 gallons. This saves 522,000 gallons of water each year. The energy savings amounts to 200 million Btu annually.

Because SSI now uses $56 \%$ less fixer with the silver recycling system, the company requires fewer shipments of fixer. Consequently, additional energy is saved by reducing the number of trips made by delivery trucks to transport new fixer to the plant.

\section{Environmental Benefits}

Besides decreasing the discharge of silver to the sewer lines, the project has also reduced the amount of $\mathrm{CO}_{2}$ emissions released into the atmosphere each year by more than 7 tons. This is a result of SSI's reduced need for heated water.

\section{Economic Benefits}

The silver reclamation unit saves more than $\$ 2,000$ per year in reduced fixer costs, and it brings in $\$ 50,000$ in revenue from the sale of reclaimed silver that formerly went down the drain. The $\$ 32,000$ cost for the deluxe Recyfix is recovered in about 6 months. The wash water recycling unit also reduces the company's annual utility bill by about $\$ 750$.

\section{Impact on Company and Industry} The Saratoga Springs plant meets the stringent discharge standards of Saratoga, New York. Its employees continue to feel good about their company and their contribution to a safer environment. The National Wildlife Federation and Seventh Generation have both expressed strong interest in using Quad/Graphics' environmentally friendly printing techniques for their magazines.

Recovering silver is applicable for all businesses involved in printing, photo processing, and medical X-rays. In fact, the medical industry could realize significant savings from a silver recovery system because X-rays have four times the silver content of graphic arts films.
WHO USES IT?

Medical facilities

Photo processors

Printers

APPLICABLE SIC CODES

2700,3800

CONTACT

Garry Simon

Saratoga Springs Imaging

(518) $581-4000$

SOURCE

Quad/Graphics 


\section{Steam Irap Testing Cuts Costs}

\section{TECHNOLOGY}

Steam trap inspection

COST SAVINGS

$\$ 1.5$ million annually

ENERGY SAVINGS

20,000 tons of coal annually

\section{ENVIRONMENTAL BENEFITS}

$\mathrm{CO}_{2}$ emissions reduction of 54,000 tons annually

\section{ADDITIONAL BENEFITS}

Reduced steam trap failure rate

to less than $12 \%$

\section{The Challenge}

The Chambers Works plant in Deepwater, New Jersey, spent more than $\$ 12$ million annually for steam and is one of DuPont's top 25 energy-consuming sites. Each of these sites has an average of 4000 steam traps. DuPont discovered that $40 \%$ of the steam traps were not performing properly, resulting in significant heat and steam losses. Given the potential magnitude of environmental and economic losses from the trap failures, the company recommended that sites implement steam trap management programs. By doing so, the Chambers Works site has saved more than $\$ 1$ million in annual steam bills.

\section{The Company}

DuPont is a large global producer of chemicals, with about 107,000 employees and annual sales of more than $\$ 39$ billion. The Chambers Works site is one of DuPont's largest facilities, employing nearly 2500 people. This site produces more than 600 different products. Chambers Works contains chemicals, fluoro products, and polymers production areas, as well as a wastewater treatment facility.

\section{The Approach}

In 1993, DuPont initiated an energy savings program to reduce its $\$ 1.5$ billion annual energy expenditure. This program, called Jump Start, focused initially on the company's 25 most energy-intensive sites, including Chambers Works. DuPont's goal in the Jump Start program was to reduce energy costs by $\$ 6.2$ million by implementing strategies that cost little or no money.
Jump Start began with a walk-through survey at each facility, which was conducted by staff from the company's Energy Engineering group and site operations personnel. With an energy savings checklist in hand, the team looked at a wide range of options for energy savings. At the Chambers Works site, one of the least costly measures with the greatest potential for savings appeared to be a more comprehensive steam trap maintenance and inspection program.

\section{Project Description}

For the Chambers Works steam trap maintenance program, DuPont used a portable steam monitoring device that it already owned. Known as Trapman and manufactured by TLV America Corporation U.S., in Charlotte, North Carolina, the device uses a sensing probe to record the ultrasonic and thermal signatures of a particular trap. Maintenance technicians simply touch the Trapman's sensor to the trap for 15 seconds, enter the trap's code number into the Trapman unit, and proceed to the next trap. The information is stored by the device's monitor and later downloaded into a computer with specialized software. This Trapman software then analyzes the data to determine the state of repair of each trap. Besides determining whether the trap requires maintenance, the program maintains a log of each trap to help pinpoint potential problem spots and identify improperly specified traps.

As part of the steam conservation project, technicians at Chambers Works replaced worn pipe insulation and repaired leaky flanges, tracer lines, and pinholes in the pipes. 


\section{Installation and Operation}

The Chambers Works site was able to implement the project very quickly. For DuPont, the expenses were negligible because it already owned the Trapman diagnostic equipment and software. The only expense was the added labor. A company interested in starting a steam conservation program using Trapman can expect to pay $\$ 10,000$ for the equipment and software.

The Trapman program is set up to remind the user when a trap is scheduled to be inspected. Because the program records the inspection results so quickly, little extra time is required from the technicians.

Although the time required to maintain the steam traps has increased slightly, the extra effort pays for itself in reduced energy costs.

\section{Energy Savings}

The amount of additional coal that would have to be burned if the steam reduction had not occurred is 20,000 tons per year.

\section{Environmental Benefits}

By not burning 20,000 tons of coal, $\mathrm{CO}_{2}$ emissions were reduced by 54,000 tons annually. In addition, $\mathrm{NO}_{\mathrm{X}}$ were reduced by more than 42 tons per year, and $\mathrm{SO}_{2}$ by more than 55 tons per year.

Chambers Works gets its steam from a new cogeneration plant with advanced technologies for emission control. The environmental benefits for older power plants would be even greater for a similar energy reduction.

\section{Economic Benefits}

Savings on the steam conservation project totaled $\$ 1.5$ million, or $12 \%$ of the total steam use at Chambers Works. Of this, the steam trap program accounts for nearly $65 \%$ of the savings, or almost $\$ 975,000$. Adding or replacing pipe insulation accounted for about $15 \%(\$ 225,000)$ of the savings, and fixing leaks accounted for about $20 \%$ $(\$ 300,000)$.

\section{Impact on Company and Industry}

Chambers Works has reduced the failure rate of its steam traps to less than $12 \%$ and expects to reduce this to less than $5 \%$. By doing so, Chambers Works has helped DuPont's Jump Start program surpass its energy savings goal. In addition, other DuPont plants have volunteered to participate in the energy efficiency program.

Steam is a valuable commodity at almost any chemical plant, as well as at refineries. Petrochemical companies can easily achieve a similar success rate by implementing an effective steam trap program.
WHO USES IT?

Chemical manufacturers

Petroleum producers

APPLICABLE SIC CODES 2800,2911

CONTACT

Dan Logan

DuPont's Jump Start

Program

(713) $358-1240$

SOURCE

DuPont 


\section{Methanol Recoveru Proceess Saves Energu and Reduces Costs}

\section{TECHNOLOGY}

Direct steam distillation system for methanol recovery

PARTNERS

U.S. Department of Energy's Office of Industrial

Technologies,

U.S. Environmental

Protection Agency,

Texas Governor's Energy

Office, and Texas Water

Commission

COST SAVINGS

More than $\$ 500,000$ annually, payback of 1.2 years

\section{ENERGY SAVINGS}

25.2 billion Btu annually

\section{ENVIRONMENTAL BENEFITS}

$\mathrm{CO}_{2}$ emissions reduction of 4390 tons annually

\section{ADDITIONAL BENEFITS}

Improved plant safety, increased productivity, improved employee morale

\section{The Challenge}

FMC Corporation's plant in Pasadena, Texas, produces hydrogen peroxide. The process of purifying crude hydrogen peroxide requires a catalyst to remove any dissolved contaminants from the processing stream. The regeneration of this catalyst involves a methanol wash and soak. During the regeneration process, the methanol is contaminated with organic solvents, trace quantities of hydrogen peroxide, and metal cations (positively charged ions). Until June 1991, companies such as FMC could dispose of contaminated methanol by burning it as waste fuel in cement kilns. However, environmental regulations have stopped this method of disposal; it must now be burned in incinerators, which is an expensive and energy-intensive process. To address rising disposal costs and increasing methanol prices, FMC developed a methanol recovery process using steam distillation.

\section{The Company}

FMC Corporation is one of the world's leading producers of machinery and chemicals for industry, government, and agriculture. The company operates 95 manufacturing and mine facilities in 18 countries. The company is divided into five segments: Industrial Chemicals, Performance Chemicals, Precious Metals, Defense Systems, and Machinery and Equipment.

\section{The Approach}

FMC Corporation, with the help of a $\mathrm{NICE}^{3}$ (National Industrial Competitiveness through Energy, Environment, and Economics) grant from the U.S. Department of Energy's Office of Industrial Technologies and the U.S. Environmental Protection Agency, implemented a method to purify, recover, and reuse contaminated methanol. The project was undertaken in conjunction with the Texas Governor's Energy Office and the Texas Water Commission.

Scientists knew that a distillation system could be used, but it would have to eliminate the buildup of oxygen from the reaction of residual hydrogen peroxide with metal ions. In addition, the system needed to be capable of handling a bottoms stream that consisted of three liquid phases: light organic, aqueous, and heavy organic. Other safety factors addressed by the system designers included minimizing or eliminating the possibility of concentrating hydrogen peroxide and keeping the oxygen content below the lower flammable limit for methanol.

\section{Project Description}

Although other distillation processes use steam or another heat source applied indirectly to an external reboiler, FMC's scientists focused on spraying steam directly into the distillation column. Not only does this process allow more than $90 \%$ of the volume of methanol to be recovered and reused, it also allows for safer operation of the distillation column. Because the steam acts as a dilutant, two potential hazards are avoided. The first is the generation of oxygen from the decomposition of hydrogen peroxide by metal ions, which can lead to a methanol fire or explosion. The second is violent decomposition or detonation reactions catalyzed by the metal ions and activated by a high concentration of hydrogen peroxide in the bottom of the column. 


\section{Installation and Operation}

Once the design was finalized, construction began in November 1991 and was completed in March 1992. The total cost to implement the methanol recovery system was $\$ 611,656$. Under the NICE ${ }^{3}$ program, the company was responsible for $\$ 479,808$ of this sum.

In July 1992, FMC conducted a demonstration of the system. The system performance exceeded the projected efficiency of $90 \%$.

\section{Energy Savings}

FMC Corporation has experienced even greater efficiencies than originally predicted. Running at $98.6 \%$ recovery efficiency, the system saves 25.2 billion Btu per year.

\section{Environmental Benefits}

The unit is saving 1.93 million pounds per year of methanol. In addition, $\mathrm{CO}_{2}$ emissions are reduced by 4390 tons from eliminating the fuel required for incineration and from complete oxidation of methanol to $\mathrm{CO}_{2}$.

\section{Economic Benefits}

FMC saves, on average, more than $\$ 500,000$ annually from reduced incineration, transportation, and methanol costs. With these savings, the payback period for the project is 1.2 years.

\section{Economic Summary Table}

\begin{tabular}{|c|c|c|}
\hline Investment Summary & Methanol Recovery & Incineration \\
\hline Added Capital Cost & $\$ 611,656$ & \\
\hline \multicolumn{3}{|l|}{ Production Costs } \\
\hline Raw Materials & $\begin{array}{l}\text { One-time methanol } \\
\text { cost of } \$ 176,000\end{array}$ & Methanol cost of $\$ 176,000$ \\
\hline \multirow[t]{2}{*}{ Steam } & $\$ 17,600$ & $\begin{array}{l}\text { Incineration costs } \\
\text { of } \$ 301,200\end{array}$ \\
\hline & $\begin{array}{l}\text { Make-up methanol } \\
\$ 17,600(10 \%)\end{array}$ & $\begin{array}{l}\text { Transportation costs } \\
\text { of } \$ 65,260\end{array}$ \\
\hline Total Production Costs: & $\begin{array}{l}\text { Year } 1=\$ 211,320 \\
\text { Out years }=\$ 35,320\end{array}$ & $\$ 542,460$ \\
\hline
\end{tabular}

\section{Impact on Company, Community, and Industry}

This methanol recovery process has resulted in increased productivity, improved

employee morale, and a safer working environment for FMC employees. FMC Corporation is incorporating it into a peroxygen manufacturing facility in Spring Hill, West Virginia. FMC also plans to implement the technology in several of its international chemical manufacturing facilities in British Columbia, Canada; La Zaida, Spain; Fuji, Japan; and Santa Clara, Mexico.

The FMC project was recognized by the Texas Water Commission as an example of the success that can be achieved through a joint industry and government effort. Both FMC and the Texas Water Commission published news releases announcing the demonstration of the methanol recovery system.

Methanol is used in many chemical production and purification processes. Approximately 436 million pounds of hazardous methanol is produced in the United States each year. With this new process, any company with a waste methanol stream can reduce its fuel requirements to transport and incinerate the spent methanol and reduce virgin methanol requirements.
WHO USES IT?

Hydrogen peroxide manufacturers

Industries with waste methanol streams

APPLICABLE SIC CODES 2000-3900

CONTACT

Harshad Thakkar FMC Corporation

(713) 474-8774

SOURCE

FMC Corporation and the U.S. Department of

Energy's Office of Industrial Technologies 


\section{COMPANY}

Manufacturer of refined waxes

AUDIT DATE

September 1993

COST SAVINGS

$\$ 371,200$ annually

ENERGY SAVINGS

148,100 million Btu annually

\section{The Challenge}

From June 1992 to June 1993, a producer of natural and synthetic waxes consumed 956,000 million Btu of energy at a cost of $\$ 2.4$ million. The company spent more than $\$ 1.9$ million of this sum to purchase natural gas. As a result of the Oklahoma State University IAC's assessment in September 1993, the company implemented actions that are saving $\$ 371,200$ annually.

\section{The Company}

The plant refines and produces 48 million pounds per year of natural and synthetic waxes for annual sales of $\$ 47.6$ million. The 120 employees operate the plant 24 hours per day, 7 days per week. The largest energy consumers in the facility ( $82.5 \%$ of total plant energy consumption) are the three natural gas boilers. Natural gas is also used for space heating and to run wedge burners. Electricity is used for refrigeration, lighting, and air conditioning, and to operate pumps and a 200-horsepower blower.

\section{IAC Recommendations}

- Repairing steam leaks would save 71,700 million Btu per year of natural gas and $\$ 132,300$ per year in energy and water costs. Returning condensate to the boiler would reduce the need for new boiler make-up water, annually saving both 30,800 million Btu and $\$ 126,300$. Replacing faulty steam traps would reduce energy requirements by 44,800 million Btu per year and save more than $\$ 106,000$ per year. Finally, insulating steam and condensate lines would result in annual savings of both 300 million Btu and $\$ 670$.

- Replacing the exterior incandescent lighting system with high-pressure sodium lamps would result in annual savings of both 400 million Btu of electricity and $\$ 5,100$.
- Recovering the waste heat from the ammonia refrigeration unit to preheat the boiler make-up water would result in annual savings of 1200 million Btu and $\$ 3,200$.

\section{Energy Savings}

Most of the savings (nearly 147,700 million Btu annually in natural gas) resulted from improving the plant's steam system. The company repaired steam leaks and faulty steam traps and made modifications to return condensate to the boiler. The company also insulated steam and condensate lines. By replacing incandescent lamps with highpressure sodium lamps, the company saves an additional 400 million Btu of electricity annually.

\section{Economic Benefits}

The company saves more than $\$ 371,000$ annually from all the energy improvements it implemented after the Oklahoma State University IAC's audit. The improvements cost approximately $\$ 99,000$, resulting in a payback of only 3 months.

Most of the savings (nearly $\$ 366,000$ per year in natural gas costs) came about by improving the plant's steam system. Implementing these measures cost approximately $\$ 94,000$, providing a 3 -month payback.

The company saves an additional $\$ 5,200$ annually in electricity from upgrading the lighting. The lighting retrofit cost $\$ 4,200$ to implement, resulting in a 10-month payback. 
Industrial Case Studies continue on following page 
Ultrafiltration/Reverse Osmosis Process Cleans Up Wastewater

TECHNOLOGY

Ultrafiltration/reverse osmosis process

PARTNERS

U.S. Department of Energy's Office of Industrial Technologies, U.S. Environmental

Protection Agency, and Ohio Department of Development

COST SAVINGS

$\$ 133,000$ annually, payback of 3 years

ENERGY SAVINGS

2.9 billion Btu annually

ENVIRONMENTAL BENEFITS

Reduced wastewater $77 \%$; reduced $\mathrm{CO}_{2}$ emissions by 177 tons annually

\section{ADDITIONAL BENEFITS}

Reduced liability, improved company image

\section{The Challenge}

Until 1992, the PPG Industries plant in Cleveland, Ohio, produced large quantities of contaminated wash water from its automotive coating process. The water was contaminated with lead-containing pigments and small amounts of organic solvents during equipment cleaning. In 1991, the PPG plant generated about 400,000 gallons of the wastewater, which was transported 175 miles to a hazardous waste incinerator for disposal, costing the company more than $\$ 380,000$. In 1992, the company installed an ultrafiltration/reverse osmosis (UF/RO) process that drastically reduced wastewater, saving the company more than $\$ 130,000$ annually.

\section{The Company}

PPG Industries is one of the largest manufacturers of automotive coatings in the world. The company employs more than 30,000 people at 90 facilities. With company sales exceeding $\$ 2.6$ billion in paint and coatings, PPG holds $20 \%$ of a $\$ 13$ billion U.S. market.

\section{The Approach}

PPG formed a Quality Action Team in 1991 to investigate ways to reduce the amount of wastewater. The team reviewed options such as distillation and dewatering by filter press or centrifuge, but these technologies did not meet the established selection criteria as well as ultrafiltration did. The team focused on ultrafiltration because of its minimal effect on labor, its ease of installation and operation, and PPG employees' existing familiarity with the application.

\section{Project Description}

With the assistance of a $\mathrm{NICE}^{3}$ (National Industrial Competitiveness through Energy, Environment, and Economics) grant from the U.S. Department of Energy's Office of Industrial Technologies and the U.S. Environmental Protection Agency, PPG developed and installed the combined UF/RO process. PPG also worked with the Ohio Department of Development on this project. Initially, an engineer from Zenon Environmental Systems of Burlington, Ontario, Canada, conducted a lab-scale test on the wastewater to determine the best type of system. A tubular UF membrane proved most effective at removing pigments without excessive plugging. Following the lab-scale test, a full-size unit (10 feet wide by 12 feet long) was installed that consisted of one Zenon UF unit (model ZPF7-48) and two Zenon RO units (model ZDPRO-900).

The water is prefiltered to remove large solids. After prefiltration, the ultrafiltration unit removes suspended solids and highmolecular-weight particles. Reverse osmosis then removes dissolved ions from the wash water. The water still contains low concentrations of ketones and other solvents, but tests show that this actually improves cleaning performance. The cleaned water is pumped into a storage tank until it is needed in the primer production areas. The remaining wastewater generated by the system is highly concentrated and can be handled effectively under the plant's conventional waste management procedures.

\section{Installation and Operation}

System installation was completed in 4.5 months. Initial operation resulted in some problems with membrane fouling, but these were resolved by operational adjustments. 
PPG does not run all wastewater generated at the plant through the UF/RO process. Some is too contaminated to benefit from the treatment and is disposed of directly. However, of the water that is treated by UF/RO, $88 \%$ is recovered for reuse.

The total cost to implement the UF/RO system was $\$ 454,000$. Of this, $\$ 288,000$ covered equipment costs; $\$ 91,000$ was spent for in-house labor; and the remainder was for materials, supplies, and laboratory testing. Annual operating costs are $\$ 175,000$.

\section{Energy Savings}

Before the system was installed, 65 trips were required each year ( 350 miles per round trip) to the hazardous waste incinerator. Now, PPG requires only about 15 trips, saving 2500 gallons of fuel. By reducing the fuel needed for transporting and incinerating waste and treating less deionized water, PPG saves about 2.9 billion Btu of energy every year.

\section{Environmental Benefits}

The plant has reduced its wastewater by 77\%. The UF/RO treated water even meets discharge standards for the public sewer district's system. In addition, using less energy to transport the wastewater reduced $\mathrm{CO}_{2}$ emissions by 177 tons per year.

\section{Economic Benefits}

Annual net savings from this system are $\$ 133,000$, which is equal to $\$ 308,000$ savings in water disposal costs less $\$ 175,000$ in operating costs. The payback period for the project is about 3 years.

\section{Impact on Company, Community, and Industry}

The success of the system has enhanced the local community's view of PPG as an environmentally responsible company. PPG received an award from the Governor of Ohio in recognition of the success of the system. The success of the UF/RO installation has also eased the way for additional waste treatment improvements in the plant. Furthermore, the system reduced the company's liability by reducing hazardous waste transportation and disposal.

The UF/RO process provides all manufacturers of water-based coating products with a cost-effective method for reducing the amount of their wastewater. The technology is also applicable to the food processing, semiconductor, and biotechnology industries.

Approximately $38 \%$ of the paint production industry produces water-based paint. If this portion of the industry were to adopt the UF/RO technology, $\mathrm{CO}_{2}$ emissions would be reduced by more than 24,000 tons per year. The net cost savings would equal $\$ 13$ million annually.
WHO USES IT?

Automotive coatings

manufacturers

Food processors

Semiconductor and biotechnology industries

APPLICABLE SIC CODES

$2000,2851,3559$

CONTACT

Maura Tinter

PPG Industries

(216) 671-7752

SOURCE

PPG Industries and the

U.S. Department of Energy's Office of Industrial Technologies

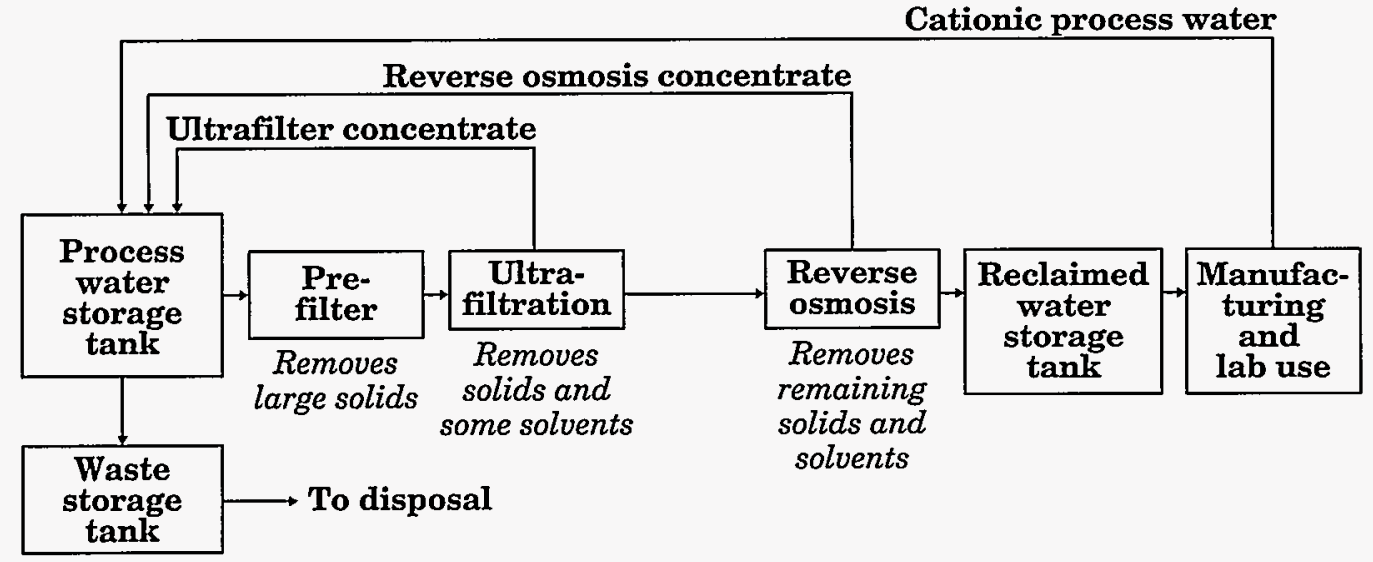




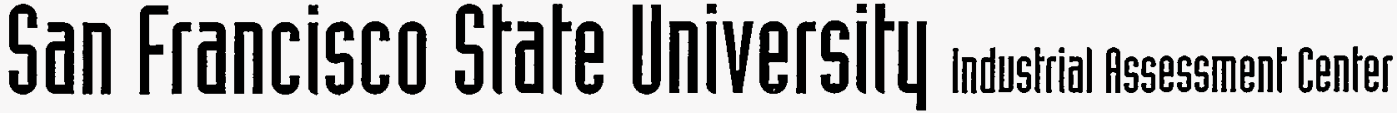

COMPANY

Manufacturer

of injection-molded

plastic parts

AUDIT DATE

February 1994

COST SAVINGS

$\$ 63,300$ annually

ENERGY SAVINGS

2110 million Btu annually

\section{The Challenge}

From May 1993 through April 1994, an injection molding company spent $\$ 264,469$ on 8837 million Btu of energy. The recommendations of the San Francisco State University IAC enable the company to save more than $\$ 63,000$ annually.

\section{The Company}

The plant produces a wide array of injection molded plastic parts. Ninety employees operate the plant 24 hours per day, 5 days per week, to produce 3 million pounds of plastic products. Annual sales amount to $\$ 4$ million. Electricity is used for processrelated equipment, lighting, and air conditioning.

\section{IAC Recommendations}

- Installing variable-speed drives on motors providing fluid power to injection molding machines would save nearly 2000 million Btu and $\$ 59,000$ annually.

- Replacing standard motors, as they burn out, with high-efficiency motors; replacing standard V-belts with notched V-belts; and installing a two-speed motor on the cooling tower fan would annually save 130 million Btu and about $\$ 3,900$.

- Installing fixed capacitance, sized to raise the power factor above 0.85 , would save about $\$ 2,100$ annually in penalty charges. (This plant is currently charged a penalty if the power factor in a billing period is less than 0.85.)

- Repairing air leaks, using synthetic oil, and implementing other air compressor system improvements would save about $\$ 3,700$ per year.
Adding economizers to the plant's five HVAC units would annually save the company both 60 million Btu of electricity and $\$ 1,800$. Economizers use outside air for space cooling when outdoor temperature and humidity levels are favorable.

- Installing lower wattage lamps, occupancy sensors, and skylights (to reduce the need for artificial lighting) would save about 180 million Btu of electricity per year and $\$ 5,300$ annually.

\section{Energy Savings}

Implementing some of the suggestions made by the San Francisco State University IAC resulted in the company saving 2110 million Btu of energy per year.

\section{Economic Benefits}

The four measures implemented from this audit save the manufacturer nearly $\$ 63,300$ annually. The total capital cost of these improvements was about $\$ 171,000$, leading to a payback of 2.7 years.

The company has realized most of the cost savings by installing variable-speed drives on the hydraulic system motors that supply the injection molding machines. This measure saves $\$ 59,000$ annually and cost $\$ 170,000$ to implement. Repairing compressed air leaks and using synthetic oil in the air compressors result in savings of about $\$ 3,700$ per year and have a 3 -month payback period. The company realizes additional annual savings of $\$ 600$ by replacing standard V-belts on motor drives with notched V-belts. 


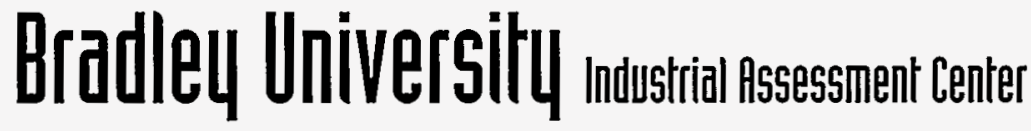

\section{The Challenge}

An aluminum product manufacturer used 20,255 million Btu of energy, for a total cost of $\$ 139,333$, during a 12 -month period ending in December 1993. Electricity accounted for the majority of the energy expenditure, consuming 6475 million Btu and costing $\$ 90,784$. The plant also consumed 11,970 million Btu of natural gas $(\$ 38,513)$, and 1810 million Btu of diesel fuel $(\$ 10,036)$. As a result of implementing conservation methods suggested by the Bradley University IAC audit in March 1994 , the company saves $\$ 24,800$ per year.

\section{The Company}

The plant produces 1.9 million pounds of aluminum castings per year and has annual revenues of $\$ 4.5$ million. It employs 32 people and operates 24 hours per day, 5 days per week. Both electricity and natural gas are used to run the major process equipment, which includes heat treat ovens, molding machines, welders, and melters. Electricity is also used for lighting, air conditioning, and compressing air. Two diesel generators provide power during peak demand periods.

\section{IAC Recommendations}

- Using its two diesel generators to power additional plant equipment until they are fully loaded could result in annual savings of $\$ 3,200$. The plant is currently using the diesel-powered generators during peak power periods to reduce electricity costs.

- Installing electronic ballasts and highefficiency lamps would save 170 million Btu of electricity per year and $\$ 2,360$ annually.
Installing high-efficiency motors to replace the existing standard motors would result in annual savings of $\$ 540$. The more efficient motors should be installed only as existing motors wear out.

Applying for tax-exempt status would save this plant a total of $\$ 7,300$ per year on purchases of electricity, diesel, and natural gas. Sales taxes are currently charged on these accounts, but fuel purchases that are used exclusively for the purpose of manufacturing a product are exempt from taxes in certain states.

\section{Economic Benefits}

The manufacturer implemented all of the recommendations made by the Bradley University IAC, leading to savings of nearly $\$ 25,000$ annually. Initial costs for the recommendations were $\$ 11,580$, leading to a payback of less than 6 months.

The facility saves $\$ 15,000$ per year in demand charges by increasing the use of a diesel-powered generator during summer peak-demand periods. The manufacturer reported actual cost savings greater than those identified by the IAC report for the measure involving the diesel-powered generators. Applying for tax-free status for process-related energy purchases saves the company $\$ 7,300$ annually in gas, diesel, and electricity charges. The manufacturer realizes additional savings of $\$ 2,400$ per year by installing high-efficiency lights and motors.
COMPANY

Manufacturer of aluminum castings

\section{AUDIT DATE}

March 1994

COST SAVINGS

$\$ 24,800$ annually 


\section{California Steel Industries, Inc.}

\section{Variable-Speed Drives \\ Cut Energy Consumption}

\section{TECHNOLOGY}

Variable-speed drives

PARTNERS

Southern California

Edison Company

\section{COST SAVINGS}

$\$ 363,000$ annually, payback of 5 years

\section{ENERGY SAVINGS}

6 million $\mathrm{kWh}$ annually

\section{ENVIRONMENTAL BENEFITS}

$\mathrm{CO}_{2}$ emissions reduction of 4100 tons annually

\section{ADDITIONAL BENEFITS}

Improved product quality by increasing effectiveness of scale removal, increased productivity, limited power disturbances through controlled acceleration

\section{The Challenge}

California Steel Industries, Inc., uses highpressure water to remove scale from hot steel strips prior to treating and reforming them. To increase the quality of its finished products, California Steel decided to upgrade from 1400-psi to 3000-psi water for this process. However, to avoid a significant increase in energy consumption from the larger pump needed to supply this pressure, California Steel installed variable-speed drives on the equipment. These drives reduce energy used for each strip during the portion of the 4-minute cycle when highpressure spray is not required.

\section{The Company}

California Steel Industries, Inc., located in Fontana, California, manufactures hotrolled-sheet steel, cold-rolled-sheet steel, and galvanized steel. The company has an annual finished capacity of 1.6 million tons and employs about 1000 people. California Steel services a broad range of customers, providing them with structural steel, pipe, and tubing for appliances, furniture, wall panels, strapping, drums and tanks, and culverts. Its products are shipped to manufacturers, contractors, and distributors throughout the western United States.

\section{The Approach}

In an effort to improve quality, increase productivity, and enhance energy efficiency, California Steel decided to modernize its 86" hot strip mill. This mill, consisting of a scale breaker, five roughing stands, six finishing stands, and three coilers, was an old facility whose equipment had not been upgraded in several years. California Steel believed that upgrading the mill's scale breaker by installing a larger pump and variable-speed drives would significantly improve product quality as well as energy efficiency. In 1993, the company applied for-and was granteda rebate from Southern California Edison Company for installing variable-speed drives.

\section{Project Description}

The old system used two 1500-horsepower, 1400-psi pumps to descale the steel. The pumps operated at constant speed, in parallel, to provide water to the spray headers. In May 1995, California Steel Industries, Inc., replaced one of these constant-speed descaling pumps with a 3250 -horsepower, 3000-psi variable-speed pump. The company also installed a variable-speed drive on the remaining pump.

When a strip of steel is present at the spray headers, the water is routed through nozzles with the pumps loaded at full speed. Approximately $14 \frac{1}{2}$ strips are rolled per hour at a rate of 4 minutes per strip. Each strip takes a minute to pass through the scale breaker, so the pumps operate $15 \mathrm{~min}$ utes per hour loaded and 45 minutes per hour unloaded. The variable-speed drives modify the speed of the pumps to match the requirements of the process.

Before the upgrade, the pump motors ran continuously at full speed. Between strips and at other idle times, water was diverted around the spray headers. Speed reduction was not possible with the previous drives at the mill operating cycles. The load fluctuations would have destroyed the motors and caused unacceptable conditions on power distribution equipment.

With the new variable-speed drives, the pump motors operate at a minimum speed during the 3 minutes of the cycle when highpressure spray is not needed. The variablespeed drive also provides controlled acceleration from the minimum speed to full speed as the strips approach the descaling spray headers, limiting power disturbances. 


\section{Installation and Operation}

The cost of the new equipment for the scale breakers was about $\$ 2$ million. Of this sum, $\$ 812,000$ was spent on the high-pressure, variable-speed pump, and $\$ 244,000$ was spent on the low-pressure equipment. The electrical installation cost $\$ 159,000$, and mechanical modifications were $\$ 620,000$. The rest of the money was spent on facility rearrangement. The system took 9 months to install and resulted in downtime of only about 5 days. Employees responsible for maintaining the system received training on the new drive and procedures. However, the operators were not affected by the change.

California Steel built a cover over the large high-pressure pump to reduce noise and provide added safety. The electronic shop in the motor room was relocated to accommodate the installation of the drive equipment and the accompanying line reactor, capacitance filters, and heat exchangers for cooling the drive.

\section{Energy Savings}

The actual electrical power consumption per ton associated with descaling has been reduced from $17.6 \mathrm{kWh} /$ ton to $15.23 \mathrm{kWh} /$ ton, for an annual savings of more than 3.8 million $\mathrm{kWh}$. The energy savings achieved as a result of including variable-speed drives as opposed to traditional constant-speed drives on the pumps amounts to $3.76 \mathrm{kWh} / \mathrm{ton}$, saving 6 million $\mathrm{kWh}$ each year.

\section{Environmental Benefits}

By using a variable-speed drive, California Steel is preventing the release of 4100 tons of $\mathrm{CO}_{2}$ emissions into the atmosphere each year.

\section{Economic Benefits}

In the first 3 months of the project, California Steel saved more than $\$ 55,000$ from reduced energy consumption and will realize an annual cost savings of $\$ 230,000$. A rebate from Southern California Edison covers more than $\$ 270,000$ of the project cost.

Had variable-speed drives not been installed with the pumps, the company's energy consumption would have increased from the added horsepower. The decision to install the variable-speed drives with this upgrade instead of using the traditional constant-speed drives translates into savings of $\$ 363,000$ each year, resulting in a payback of about 5 years.

\section{Impact on Company and Industry}

The use of variable-speed drives made the modernization of California Steel's hot strip mill cost effective. The company was able to improve the quality of its work while saving energy. The improved product quality from the large, high-pressure pump has been confirmed in all of the company's finish mills and has contributed to a record increase in productivity levels.

Variable-speed drives have wide industrial applications aside from their use for steel making and continuous casting. For example, the pulp and paper, textile, steel, rubber and plastics, food processing, metal casting, transportation, and printing industries all have processes that could benefit from the use of variable-speed drives.
WHO USES IT?

Food processing

Metal casting

Printing

Pulp and paper

Rubber and plastics

Steel

Textiles

Transportation

APPLICABLE SIC CODES

$2000,2200,2600$,

$2700,3000,3300$

CONTACT

Dennis Poulsen

California Steel Industries, Inc. (909) 350-5973

SOURCE

California Steel Industries, Inc. 


\section{Infrared Druer \\ Speeds Up Production \\ of Mold Coatings}

TECHNOLOGY

Infrared mold wash

coating system

PARTNERS

Electric Power

Research Institute, BGK Finishing Systems

COST SAVINGS

$\$ 9,000$ annually, payback of 1.3 years; potential savings of $\$ 4$ million annually to industry

\section{ENERGY SAVINGS}

$120,000 \mathrm{kWh}$ annually; potential savings of

54 million $\mathrm{kWh}$ annually to industry

\section{ENVIRONMENTAL BENEFITS}

$\mathrm{CO}_{2}$ emissions reduction of 27 tons annually

\section{ADDITIONAL BENEFITS}

Improved mold and casting quality, space savings, improved work environment, greater flexibility with heating input

\section{The Challenge}

Responding to regulatory constraints and pollution prevention initiatives, foundries are moving toward using water-based refractory coatings on sand molds and cores rather than solvent-based coatings. Waterbased coatings are nontoxic and less costly. However, they take 20 minutes to dry in conventional electric drying ovens, which creates a bottleneck in production. The infrared mold-coating dryer at Decatur Foundry, Inc., eliminated this problem by reducing the drying time as much as $85 \%$.

\section{The Company}

Decatur Foundry is a gray and ductile iron foundry in Decatur, Mlinois. It specializes in iron castings for electric-motor frames and parts as well as pump components. The plant employs 75 people and produces 1000 tons of castings per month. Decatur's annual sales are $\$ 5.9$ million. Total sales in 1993 for ductile and gray iron castings in the United States were $\$ 4.5$ billion.

\section{The Approach}

In its search for options to reduce drying time, Decatur Foundry approached Illinois Power Company. Illinois Power took Decatur's challenge to the Electric Power Research Institute's Center for Materials Production (CMP) and to BGK Finishing Systems in Minneapolis, Minnesota. BGK, a manufacturer of short-wavelength infrared systems, recommended that Decatur's electric resistance dryer be replaced with an infrared/forced-air unit. Based on BGK's pilot test at a nearby foundry, CMP decided to fund the development of a prototype unit that was installed at Decatur. Decatur was attracted by the flexibility of the infrared drying system. Because the plant produces a wide variety of castings weighing from 1 to 5000 pounds, Decatur was interested in a system where the heating input could be varied easily and quickly.

\section{Project Description}

With the assistance of the Electric Power Research Institute and BGK, Decatur installed a 24-kW mold dryer that uses infrared heat. The infrared emitters radiate heat directly to the mold surface (not the surrounding air), driving off water vapor in the process. Then, forced air separates the evolving vapor from the heated mold surface.

The drying cycle begins when the mold enters the heating zone. No initial heat-up time is required. Once the drying cycle is complete, the system shuts off automatically. The cycle lasts approximately 3 minutes17 minutes less than the time required to dry the mold coatings using conventional electric heaters.

\section{Installation and Operation}

BGK installed the unit at Decatur in 3 working days without interrupting production. The total cost of the system was $\$ 12,000$.

The infrared dryer not only saves energy and reduces drying time, it has also resulted in additional benefits for Decatur Foundry. For example, the infrared drying unit is considerably smaller than the previous dryer, so it freed up valuable floor space. The size of units range from 9 square feet to 64 square feet, depending on the model. 
The system can also dry the coating in deep cavities and mold pockets, which improves the mold and casting quality. Furthermore, because the system concentrates heat on the mold, less heat is emitted to the surrounding area, creating a more comfortable work environment. Finally, because there are fewer hot surfaces, workers are much less likely to experience burns.

BGK was so confident of the operational success of the infrared dryer that the company agreed to reimburse Decatur for the cost of the system if it did not operate as expected. However, because the system works so successfully, Decatur has purchased three more units.

\section{Energy Savings}

Decatur's yearly energy costs for mold drying dropped from $\$ 12,000$ to $\$ 3,000$, a savings of $120,000 \mathrm{kWh}$ per year. Savings come from the ability of the unit to turn off after the drying is complete and the wattage required for operation is reduced. The previous system required $67 \mathrm{~kW}$ to operate, but the new infrared dryer requires only $24 \mathrm{~kW}$.

\section{Environmental Benefits}

The savings in electricity use translate into annual reductions in $\mathrm{CO}_{2}$ emissions of 27 tons.

\section{Economic Benefits}

Decatur realized cost savings of $\$ 9,000$ annually from reduced energy consumption, and the foundry was therefore able to pay back the cost of the system in a little more than a year.
Impact on Company and Industry

Approximately 1500 foundries in the United

States use mold wash coatings. The use of this technology by $30 \%$ of the mold wash coatings industry could result in annual savings of 54 million $\mathrm{kWh}$ and more than $\$ 4$ million.

Decatur has completely switched over to infrared mold curing and now has four lines. The manufacturer, BGK, has already sold eight systems and is talking to several other interested companies.

The infrared dryer allows foundries to use the environmentally safe, water-based coatings while not compromising production schedules. And the low capital costs make this technology affordable for most metal casting companies. The technology is applicable to green sand coatings used for larger castings as well as the no-bake type used at Decatur.
WHO USES IT?

Aluminum castings companies

Iron castings companies

Metal coatings companies

APPLICABLE SIC CODES

$3321,3322,3325$

\section{CONTACT}

Terry Young

Decatur Foundry, Inc.

(217) 429-5261

SOURCE

Decatur Foundry, Inc., the Electric Power Research Institute's Center for Materials Production (fact sheets TA-103987, IN-102916), and BGK Finishing Systems 
CONSTEEL Steelmaking Technologl Improves Productivitu

TECHNOLOGY

CONSTEEL scrap preheating method

BENEFITS

Energy savings, improved productivity, reduced tap-to-tap time by 30 minutes

APPLICABLE SIC CODES

$3312,3313,3315$ 3316,3317

\section{SOURCE OF CASE STUDY}

Electric Power Research Institute's Center for Materials Production, TechApplication, CMP-088, 1993.

\section{The Challenge}

The electric arc furnace (EAF) is the primary scrap-melting process for minimill steel producers. EAF steel production now accounts for about $38 \%$ of total annual steel output in the United States.

Although electricity is the major energy input, other energy sources, including oxy-fuel burners, and oxygen and carbon injection, have been used to make the furnace more energy efficient, productive, and cost effective. However, only about $60 \%$ of the total heat energy is used to heat and melt the steel. Of the balance, about $20 \%$ is lost with the waste gases.

Efforts have been made, primarily in Europe and Japan, to recapture some of this lost heat by using the waste gases to preheat the steel scrap prior to furnace charging. These installations have been only marginally successful, however, due to high maintenance, preheater emissions, and problems associated with coordinating preheater output with furnace needs. In spite of these difficulties, new scrap preheating techniques are continually being investigated.

In the mid-1980s, a prototype for a new scrap preheating method, CONSTEEL, was demonstrated at Nucor's Darlington, South Carolina, steel plant. In 1989, Florida Steel completed the first commercial installation of the CONSTEEL process.

\section{The Company}

Florida Steel is a Tampa-based steelmaker employing 2000 people. The company operates five electric furnace mills and a number of processing facilities throughout the United States. Annual raw steel capacity of the mills is approximately 1.7 million tons. Steel products include reinforcing bar, wire fabric, steel doors and hardware, railroad spikes, and nails.

The Charlotte, North Carolina, plant employs 260 people and produces 300,000 tons of finished reinforcing bar, rounds, flats, squares, and angles.

\section{The Approach}

Florida Steel's Charlotte plant has been melting carbon steel for reinforcing bar applications since 1961. Two standard 30-ton (18 MVA) electric arc furnaces were used for steel melting. In 1987, Florida Steel decided to install a new melting facility using the CONSTEEL process to achieve these goals:

- The melt shop and surrounding environment had to be significantly improved to meet requirements established by the EPA and local government.

- Energy savings and productivity improvements had to be realized with the installation.

For the CONSTEEL installation, Duke Power provided some direct financial funding and in-kind support for the project to evaluate the unit's performance. Duke Power was also very involved in fine tuning the process for the new furnace. 


\section{Project Description}

The Charlotte plant replaced its two EAFs with a single 30-MVA, 80-ton EAF and installed the CONSTEEL technology. The plant also converted one of the original furnaces to a ladle-refining furnace and constructed a new building for housing the melt shop. All improvements were focused on meeting the energy, productivity, and environmental goals for the plant.

The CONSTEEL process is a patented continuous-feeding, preheating, and melting steelmaking technology developed by Intersteel Technology, Inc., in Charlotte. A major component of the process is the long, conveyorized preheater used to feed and preheat the scrap. This preheater is 100 feet long. The preheater charges shredded scrap, \#1 and \#2 scrap, turnings, and light structural scrap at a rate of 2000 pounds per minute directly through the side of the furnace. Hot furnace gases leaving the furnace travel through the preheater (countercurrent to the scrap-charge direction) and into the ductwork leading to the baghouse. This arrangement allows preheating of the scrap as it is continuously fed into the furnace. One characteristic of the process is that the furnace taps approximately 45 tons, leaving a 35-ton heel for the next heat. During cold start-up, or whenever the conveyor and preheater are down, the furnace can be conventionally top-charged.

\section{Energy Savings}

Based on several years of operations, the CONSTEEL process has achieved the goals set for its installation. Electric energy use for the $\mathrm{EAF}$ has been in the range of $345 \mathrm{kWh} /$ ton, compared to about $450 \mathrm{kWh} /$ ton for conventional EAF operations. During melting, additional energy is added with oxygen injection at a rate of about 620 cubic feet/ton. The energy savings is attributed to the use of the waste gases for preheating and continuous feeding, which has eliminated the need for opening the furnace roof.

\section{Additional Benefits}

The continuous feeding feature of CONSTEEL has also resulted in significant productivity improvements. Tap-to-tap times for the furnace average less than $60 \mathrm{~min}$ utes, compared to almost 90 minutes when the furnace was operating without CONSTEEL. The installation has enabled the plant to meet EPA and local regulations for carbon monoxide emissions. Other benefits realized include excellent furnace electrode consumption of 4.5 pounds a ton, reduced electric power supply disturbances, and reduced shop noise. Overall, the CONSTEEL installation has exceeded the expectations of Florida Steel management.

For more information, contact the Electric Power Research Institute's Center for Materials Production, Pittsburgh, Pennsylvania, at (412) 268-3243. 


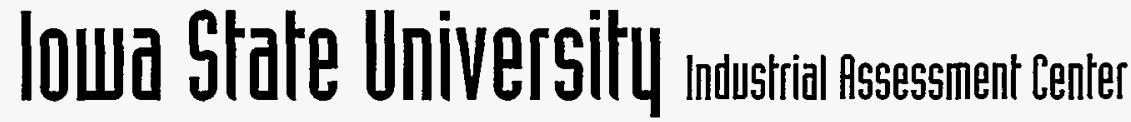

COMPANY

Producer

of iron castings

AUDIT DATE

June 1994

COST SAVINGS

$\$ 96,000$ annually

ENERGY SAVINGS

1180 million Btu annually

\section{The Challenge}

During a 12-month period ending in November 1993, an iron casting company used 205,290 million Btu of natural gas and electricity a year in its production process, costing the company more than $\$ 1.5$ million annually. After the IAC at Iowa State University conducted an assessment of the company's energy usage, the manufacturer implemented recommendations that have resulted in annual cost savings of $\$ 96,000$.

\section{The Company}

The company manufactures valves, pipe fittings, and fire hydrants. The plant is operated by 350 employees who produce 18,600 tons of product annually, for gross annual sales of $\$ 70$ million. The facility has two main locations: a foundry and a machining plant. The major energy users at the foundry are the arc melters, the holding furnaces, and the ladle heaters. The arc melters use electricity, while the furnaces and the ladle heaters use natural gas. At the machining location, the paint ovens and the air compressors are the major electrical energy users.

\section{IAC Recommendations}

- Purchasing gas directly from a contract (wellhead) gas supplier or gas broker would result in annual savings of $\$ 64,000$. This gas would be delivered through the local utility for a small transport charge.

- Lowering the air pressure control setting on the air compressors at the foundry and the machining plant would result in annual savings of 941 million Btu and $\$ 8,200$; repairing leaks in the compressed air lines on a regular basis would save an additional 80 million Btu annually and $\$ 980$ per year.
- Replacing standard lamps with highefficiency ones as the existing lamps burn out and installing occupancy sensors in the office area could result in total savings of 90 million Btu per year and $\$ 960$ annually.

- Installing high-efficiency motors as the existing standard ones burn out, reducing the paint booth operating time, and charging the forklift batteries during offpeak hours to reduce demand costs would save a total of 180 million Btu annually and $\$ 2,500$ per year.

\section{Energy Savings}

Improvements to the compressed air system (lowering compressor air pressure and reducing compressed air leaks) have resulted in annual savings of more than 1000 million Btu of electricity. Installing energy-efficient lighting and motors saves an additional 160 million Btu annually.

\section{Economic Benefits}

This plant saves more than $\$ 96,000$ annually from implementing four of the recommendations made by the Iowa State University IAC. The capital cost for these measures totaled $\$ 7,220$, resulting in a 1-month payback.

The manufacturer saves $\$ 85,000$ per year by purchasing natural gas directly from a contract gas supplier instead of from the local utility. Improvements to the compressed air system have resulted in annual savings of $\$ 9,200$. By installing energyefficient lighting and energy-efficient motors, the company is saving an additional $\$ 1,800$ per year. 
Industrial Case Studies continue on following page 
Scrap Metal Hecucling and Water Reuse Result in Significant Cost Savings

TECHNOLOGY

Scrap metal recycling

and water reuse

COST SAVINGS

More than

$\$ 1.9$ million annually

ENVIRONMENTAL BENEFITS

$26 \%$ reduction in wastewater

\section{ADDITIONAL BENEFITS}

Improved employee morale

\section{The Challenge}

In 1989, LTV-the predecessor company of Republic Engineered Steels, Inc.-was facing Chapter 11 bankruptcy. To improve its dire financial situation, LTV decided to focus on producing flat rolled steel and sell off its bar steel division, now known as Republic Engineered Steels, Inc.

The employees at Republic acquired the company under an employee stock ownership plan. When the 1990 recession struck, the company was faced with the prospect of significant layoffs, or alternatively, cutting costs by $\$ 80$ million to remain viable. To avert layoffs, the company initiated a successful cost-savings program. Two projects, sorting scrap metal and reducing water use, have already cut costs and saved the company money.

\section{The Company}

Republic Engineered Steels, Inc., manufactures special quality bars of carbon steel, stainless steel, tool steel, and a variety of alloy steels. The company's sales in fiscal year 1995 exceeded $\$ 800$ million. With 10 plants in 6 states, Republic garners about $10 \%$ of the U.S. market for special highquality engineered bars.

\section{The Approach}

Faced with a tightening economy, in 1991 Republic initiated Target 80 . This program set out to permanently reduce structural costs by $\$ 80$ million annually by encouraging employees to identify process changes, work practices, and other procedures that would eliminate waste, and thereby reduce costs. Target 80 is part of Republic's participative management approach. Through it, Republic hoped not only to cut costs but also improve the adversarial relationship between management and employees. Republic began by soliciting suggestions for improvements from every employee. In the first 20 months, more than 1000 suggestions were made. Of these, about half were implemented.

Two fairly simple measures suggested by the Canton, Ohio, plant resulted in huge cost savings. Workers in the melt shop recommended sorting the scrap by steel composition before remelting it. Another suggestion was to examine all areas of water use at the facility to reduce water treatment and disposal costs.

\section{Project Description}

Republic uses electric arc furnaces to melt scrap steel from various sources and form it into new product. Scrap is leftover steel from recycling autos, appliances, and other steel products. Scrap also comes from steel plants as cut-off ends or steel that is fouled. Prior to Target 80 , the scrap was put into one pile in the foundry and added to the melt as needed. Of the 200,000 tons of scrap internally generated each year, about 90,000 tons were very high-quality steel with low levels of impurities. This high-quality steel, however, lost its value when added to the melt and mixed with lower quality steels.

The Target 80 suggestion sought to preserve the high quality of some of the scrap. Republic began sorting the different grades of steel into separate piles before melting, then dedicated each melt to a different grade of steel. As a result, metallurgists now do not have to work as hard to remove impurities from the melt. This change saved both labor and energy.

The other cost-saving suggestion involved the use of water for cleaning. By changing from live steam cleaning to a dip rinse system, the plant reduced energy costs as well as wastewater generation. Recycled rinse water is sprayed on the steel bars after 
they emerge from an acid pickle liquor that removes any scale or oxides. Then, the bars are rinsed with fresh water. The spray water returns to the holding tanks and is reused. By adding a chemical inhibitor called Kleanrite 50, the plant extended the wash. water life. When the first rinse water no longer cleans adequately, the water is disposed of off-site. The second rinse bath is used to dilute the pickle liquor. This measure reduced wastewater by $26 \%$ in 1 year.

\section{Installation and Operation}

The scrap metal sorting project began full scale at the Canton, Ohio, plant after a week-long implementation period. During this week, the company trained employees on how to separate the scrap into the appropriate piles. In addition, the company created additional space in the melt shop for the different types of scrap. The only cost to implement the sorting system was the 1-week training period.

The water reuse process took about 4 months to fully implement.

\section{Energy Savings}

Energy consumption required for steam was reduced by changing to a dip rinse system. The scrap sorting project also saved energy. By starting with a known grade of steel in the steel-malking furnace, the time spent adjusting the chemical composition was reduced. Thus, the energy required to keep it hot was also reduced.

\section{Environmental Benefits}

The project resulted in reduced wastewater and decreased air emissions from the lower energy use required for the metallurgy furnace and for steam generation.

\section{Economic Benefits}

Prior to Target 80, Republic had been turning 90,000 tons of high-quality \#1 steel, valued at $\$ 106$ per ton, into scrap-quality steel ( $\$ 85$ per ton) by mixing the two together. Simply by sorting the scrap by composition, the company was able to realize nearly $\$ 1.9$ million in annual savings.

The Canton plant spends $\$ 750,000$ each year for city water. By instituting a water conservation program, it was able to cut this by $\$ 20,000$. While not all of the savings were due to changes in the pickling rinse process, this one change accounted for a significant portion.

\section{Impact on Company and Industry}

Target 80 has since been replaced by a new Target 60 program. Target 80 resulted in approximately $\$ 50$ million in annualized cost savings. Target 60 -designed to reduce costs by another $\$ 60$ million-has achieved more than $\$ 20$ million of its objective. Partly because of these employee-instituted savings projects, no major layoffs have occurred at Republic in its 6 years as a stand-alone company. In addition, it has reduced its debt significantly and, in early 1995, it conducted an initial public offering of common stock. The employees continue to own $60 \%$ of the common stock, and cost savings through Target 80 and Target 60 programs benefit them as stockholders and as employees.

The company received an award from the U.S. Department of Labor in 1991 for instituting a program that improved the relationship between workers and management.

The scrap sorting and water reuse projects could be easily implemented by manufacturers of other ferrous and nonferrous products that use a variety of alloy compositions. The approach to these projects, however, has much broader applications. Any company can benefit from the knowledge of its workers to cut costs.
WHO USES IT?

Metal manufacturers

APPLICABLE SIC CODE 3316

CONTACT

Harold V. Kelly

Republic Engineered

Steels, Inc.

(216) 837-6000

SOURCE

Republic Engineered Steels, Inc. 


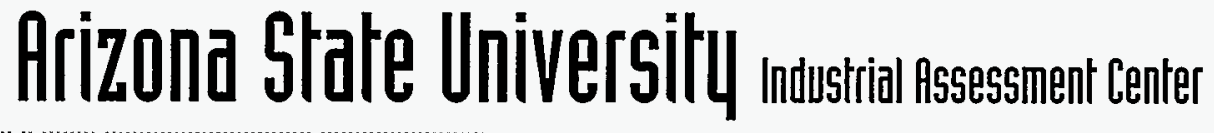

COMPANY

Producer of anodized and plated metal parts

\section{AUDIT DATE}

November 1992

\section{COST SAVINGS}

nearly $\$ 62,000$ annually

\section{ENERGY SAVINGS}

58 million Btu annually

\section{The Challenge}

From January 1992 to January 1993, a metal parts manufacturer consumed 8508 million Btu of electricity for a cost of $\$ 255,500$. In November 1992, the Arizona State University IAC performed an industrial assessment. By implementing several of the IAC recommendations, the company now saves nearly $\$ 62,000$ annually.

\section{The Company}

The plant produces 1200 orders of anodized and plated metal parts per year with annual sales of $\$ 10$ million. It employs 200 people and operates approximately 5900 hours per year. The entire facility, which consists of two buildings, is air conditioned. The major process equipment includes a 100-ton chiller, a cross-flow cooling tower, three air compressors, and four fume scrubbers.

\section{IAC Recommendations}

- Installing a cogeneration system to produce electricity and to provide steam heating for the plating tanks, which currently are heated electrically, would save $\$ 147,000$ annually in electricity costs. A system incorporating a naturalgas-fired reciprocating engine with a synchronous generator appeared most appropriate for this facility.

- Replacing the plating and anodizing tank electric immersion heaters with steam jacket heaters would save $\$ 54,500$ per year. A boiler, sized for the required thermal load for heating the tanks, would provide the steam.

- Installing variable-frequency drive controls on the fume scrubber fans would reduce the motor power consumption by $37 \%$. This corresponds to annual savings of both 169 million Btu and $\$ 5,000$.
Installing shades over the air-conditioner condensers, using synthetic lubricants for the compressors, and installing two-speed motors on the cooling tower fan would conserve 32 million Btu per year and save $\$ 990$ annually.

- Replacing the current fluorescent lighting in the plant with high-efficiency (low-wattage) lighting would result in annual savings of both 33 million Btu and $\$ 1,100$.

\section{Energy Savings}

The plant saves 33 million Btu of electricity per year by improving the lighting efficiency. The plant saves another 25 million Btu of electricity annually by installing shades over air-conditioner condensers and using synthetic lubricants.

\section{Economic Benefits}

The manufacturer saves nearly $\$ 62,000$ annually by implementing four of the recommendations made by the Arizona State University IAC. The total capital cost for these measures was $\$ 41,200$, resulting in an 8-month payback.

The majority of the savings realized by the plant resulted from replacing electric immersion heaters in plating and anodizing tanks with steam jacket heaters. This measure led to annual savings of $\$ 60,000$, with an initial cost of $\$ 40,000$. Improving the lighting efficiency of the plant saves $\$ 1,000$ per year. The manufacturer saves more than $\$ 760$ annually by installing shades over air-conditioner condensers and using synthetic lubricants. The implementation cost for these measures was $\$ 1,200$, resulting in a payback of less than 8 months. 
Industrial Case Studies continue on following page 


\section{Colorado State University mudstrial sessessner tenter}

COMPANY

Manufacturer of screw machine products

\section{AUDIT DATE}

August 1994

\section{COST SAVINGS}

$\$ 14,250$ annually

\section{ENERGY SAVINGS}

560 million Btu annually

\section{ENVIRONMENTAL BENEFITS}

Reduces solvent air emissions by 20,000 pounds annually

\section{The Challenge}

A company manufacturing screw machine products for hydraulic systems consumed 17,160 million Btu at a total cost of $\$ 215,650$ from August 1993 to August 1994. Electricity consumed the largest portion of the company's energy load, at 11,970 million Btu and $\$ 189,550$. In August 1994, the Colorado State University IAC conducted an audit at the company and noted several energy efficiency and waste minimization opportunities. As a result of implementing some of the IAC recommendations, the manufacturer saves $\$ 14,250$ annually.

\section{The Company}

The company employs 140 people who produce 37.7 million parts annually. Gross sales amount to $\$ 8.5$ million per year. Electricity is used for operating all mechanical processing equipment (such as screw machines and pumps), space cooling in the office area, lighting, and compressing air. Natural gas is used by space-heating equipment and a brazing oven.

The major hazardous waste stream at this plant is spent ion exchange resins from the wastewater treatment area. Other significant waste streams include solvent air emissions, waste liquid cleaning solvent, spent water-soluble cutting fluid, and spent floor dry (absorbent clay granules used to clean oil spills).

\section{IAC Recommendations}

- Replacing the existing standard lamps and ballasts with high-efficiency lamps and electronic ballasts would save 700 million Btu of electricity per year and more than $\$ 9,000$ annually.
Replacing standard V-belt drives on motors with high-quality synchronous belt and sprocket drives would save approximately 370 million Btu of electricity annually and $\$ 5,850$ per year. Because synchronous belts do not require high belt tension, they save energy by reducing belt slippage on drive sheaves and reducing loads on bearings.

- Replacing standard motors with highefficiency motors, insulating hot tanks to reduce heat losses from the tank surfaces, and using outside air for the air compressor intakes would save a total of $\$ 5,300$ per year.

- Recovering chromic acid from drag-out in the rinse tank by installing a closed-loop chromium recovery system would eliminate 23,000 pounds per year of spent anion resin from the wastewater treatment area and save $\$ 15,000$ annually in raw material and disposal costs. At this plant, the steel parts are cleaned, zinc plated, and chromate conversion coated, all in acidic process solutions. Between each process, the parts are rinsed in water baths. The used water is then sent to the wastewater treatment area, where the chromium is removed by anionic exchange columns. The recovered chromic acid could then be used to maintain the bath level of the conversion coating tanks. 
Installing a spring-loaded lid on the parts washer would reduce the potential for leaving the lid open, and thus reduce the amount of solvent that evaporates. This measure would reduce solvent air emissions by 20,300 pounds annually and save $\$ 5,400$ per year. Currently, the parts washer (which contains a cleaning solvent) is left open when it is not being used.

- Replacing the floor dry with absorbent pads and a wringer could reduce nonhazardous solid waste and would eliminate approximately 48,700 pounds of solid waste annually, saving $\$ 3,300$ per year.

- Implementing a formal cutting fluid management program on machines using aqueous cutting fluids would eliminate 43,300 pounds of waste per year and save $\$ 2,640$ annually in reduced cutting fluid purchase, labor, and disposal costs. This program would include installing a coolant-recovery system, an electrolytic bacteria eliminator, and a jet pump return system, and would involve regular maintenance, cleaning, and tracking.

a Installing a cation removal system on the chromium conversion tanks would extend the life of the chromium solution, reducing waste by 430 pounds per year and saving $\$ 620$ annually in raw material costs.

\section{Energy Savings}

By implementing many of the recommendations of the IAC, the company saves 560 million Btu per year and eliminates 68,800 pounds of waste annually in the form of floor dry and solvent air emissions.

\section{Economic Benefits}

The manufacturer achieves annual savings of $\$ 14,250$ from the industrial assessment performed by the Colorado State University IAC. The total implementation cost was $\$ 4,100$, resulting in a payback of 4 months. Installing high-efficiency motors and insulating the hot tanks in the brazing area and plating lines saves $\$ 3,500$ per year with a payback of 11 months. Installing highefficiency lamps and ballasts as the present ones burn out saves $\$ 4,460$ annually with an immediate payback. In addition, by replacing floor dry with absorbent pads and a wringer, the company annually saves $\$ 800$ and reduces the plant waste by 48,500 pounds per year. Modifying the parts washers to reduce the amount of evaporated cleaning solvent saves $\$ 5,400$ per year and reduces solvent air emissions by more than 20,000 pounds annually. 


\section{Greenfield Industries}

Vaccum Furnace Saves

Energu and Enables
Company to Aemain
Competitive

TECHNOLOGY

Vacuum furnace

PARTNERS

Western Massachusetts

Electric Company

COST SAVINGS

More than $\$ 100,000$ annually, payback of less than 2 years

\section{ENERGY SAVINGS}

1.5 million $\mathrm{kWh}$ annually

ENVIRONMENTAL BENEFITS

$\mathrm{CO}_{2}$ emissions reduction of 339 tons annually, eliminated hazardous waste

\section{ADDITIONAL BENEFITS}

Increased productivity, improved employee morale

from safer work environment, better product quality through improved temperature control

\section{The Challenge}

Originally, the Greenfield Industries plant in Massachusetts used a series of molten salt baths to harden and strengthen industrialgrade taps and dies used to create threaded products. This process resulted in a washwater stream contaminated with salts containing barium and cyanide ions. Consequently, the plant was rarely in compliance with strict limits on discharges to the public treatment system. In addition, Greenfield's utility bills were extremely high-more than $\$ 1$ million per year. To remain operational and competitive, Greenfield realized it needed to make changes to reduce the use of chemicals and energy. In 1992, the plant installed new vacuum furnaces and a fluidized sand bed process that eliminated the use of barium and cyanide and reduced electrical bills.

\section{The Company}

Greenfield Industries, headquartered in Augusta, Georgia, owns about 20 plants in the United States and Europe. The Greenfield Industries plant in Greenfield, Massachusetts, is a 121-year-old manufacturer of industrial-grade taps and dies, employing 150 workers.

\section{The Approach}

In 1989, Greenfield Industries was restructuring its plant in Greenfield, Massachusetts, to cut costs in the face of strong foreign competition and a slow U.S. economy. At the same time, the local utility, Western Massachusetts Electric Company, had recently launched its Energy Action Program. Under this program, the utility provides technical expertise and financial incentives to its customers for implementing energy efficiency improvements. An energy analysis revealed that the molten salt heat treatment baths demanded a large portion of the electricity used by the plant. The plant had wanted to replace these salt baths with a new vacuum furnace for the last few years. With the utility incentive, Greenfield was able to convince its parent company to make the investment.

\section{Project Description}

Under the Energy Action Program, Greenfield installed two new vacuum furnaces, in place of the molten salt baths, and a fluidized sand bed. The new batch process entails loading baskets of taps into the airtight furnace. Then, vacuum pumps expel any atmospheric contaminants from the furnace. An electrically heated inert gas, nitrogen, is introduced into the furnace to heat the taps, causing the required change in microstructure. Before being unloaded, the taps are cooled by circulating cold nitrogen.

The fluidized sand bed replaced a specialized heat treatment process that was used to manufacture one of the company's products and eliminated the need to use cyanide in the manufacturing process.

\section{Installation and Operation}

Furnace installation was completed by August 1992. The furnace cost about $\$ 808,000$, and the fluidized sand bed cost $\$ 64,000$. The company paid $18 \%$ of the total cost, and Western Massachusetts Electric Company covered the remaining sum.

The large vacuum furnaces (12 feet by 14 feet), holding about one ton of product, had to be modified after installation to ensure proper cooling of the steel. After the entire ton of steel is heated to $2180^{\circ} \mathrm{F}$, it is cooled by nitrogen to $1800^{\circ} \mathrm{F}$ in 2 minutes. 
If cooled too slowly or too quickly, the steel will not meet specifications. To ensure carefully controlled cooling, Greenfield installed a 200-horsepower blower to circulate the nitrogen. The result was better temperature control and better product quality.

\section{Energy Savings}

Greenfield's previous heat-treatment process consumed 1.8 million $\mathrm{kWh}$ annually. The new vacuum furnace uses six times less energy ( 0.3 million $\mathrm{kWh})$, resulting in annual energy savings of 1.5 million $\mathrm{kWh}$. Most of the savings result from the furnace not being kept hot when idle. Using the vacuum furnaces has caused an $18 \%$ drop in annual electrical costs at the plant.

\section{Environmental Benefits}

The annual energy savings of more than 1.5 million $\mathrm{kWh}$ reduces $\mathrm{CO}_{2}$ emissions by 339 tons per year. In addition, the plant's improvements eliminated the use of barium and cyanide and their resulting emissions.

\section{Economic Benefits}

The project saves Greenfield more than $\$ 100,000$ annually. Reduced electricity costs account for $\$ 88,800$, while elimination of the purchase and disposal of hazardous chemicals accounts for $\$ 20,000$. With the utility's rebate, the plant was able to pay back its investment in less than 2 years.

\section{Impact on Company, Community, and Industry}

In 1994, Greenfield Industries received an award from the U.S. Department of Energy's Office of Energy Efficiency and Renewable Energy for installing the vacuum furnace.

As a result of the improvements, the plant remained a valuable contributor to the local economy by preserving 150 jobs. The plant worked with the U.S. Environmental Protection Agency, the Massachusetts
Department of Environmental Protection, and the town of Greenfield during installation to ensure that the new system complied with environmental regulations. Before the project, the plant was the largest producer of hazardous waste in Franklin County; now it does not produce any. Eliminating the hazardous waste creates a safer environment for the surrounding community.

The project not only saved the plant from closing or relocating, it also improved employee morale and working conditions. For example, the furnaces emit less heat, creating a more comfortable environment. Furthermore, employees no longer have to handle hazardous wastes, which improves workers' health and safety.

Other metal-working companies could achieve similar results by implementing the vacuum furnace technology. This technology is already used internationally by most of the German steel manufacturers. The furnaces may also be used as an alternative to solvent cleaning of steel parts.

Greenfield Industries holds one-fifth of the U.S. market in industrial-grade taps and dies. If the rest of the U.S. high-volume taps manufacturers installed new vacuum furnaces, the total annual cost savings would be more than $\$ 500,000$ and the cumulative amount of energy saved each year would be 7.5 million $\mathrm{kWh}$. In addition, annual $\mathrm{CO}_{2}$ emissions would be reduced by 1700 tons.
WHO USES IT?

Metal-working companies

APPLICABLE SIC CODES

3400,3500

CONTACT

David Bliss

Greenfield Industries

(413) $772-3261$

SOURCE

Greenfield Industries, Western Massachusetts Electric Company, and the U.S. Department of Energy's Office of Energy Efficiency and Renewable Energy 


\section{Hyde Tools}

Wastewater Recucling and Energu-Efficient Lighting Result in Bottom-Line Savings

TECHNOLOGY

Wastewater recycling system; energy-efficient lighting

\section{BENEFITS}

Improved product quality, savings of $\$ 69,870$ from wastewater recycling and $\$ 48,000$ from lighting retrofit

\section{APPLICABLE SIC CODES}

3400,3500

\section{SOURCES OF CASE STUDY}

"Finding Green in Clean:

Progressive Pollution

Prevention at Hyde Tools,"

Joseph E. Paluzzi and

Timothy J. Greiner,

Total Quality Environmental

Management, pp. 283-290,

Spring 1993.

Greening the Building

and the Bottom Line,

Joseph J. Romm,

U.S. Department of Energy and William D. Browning, Rocky Mountain Institute, 1994.

\section{The Challenge}

One step of Hyde Tools' manufacturing process involves immersing metal parts in a liquid potassium chloride bath at $1700^{\circ} \mathrm{F}$ for 2 minutes. Following the bath, the parts are placed in oil for quenching. To remove the oil, the parts are sent through a wash/ rinse cycle and two counter-current rinses. Using a total quality environmental management approach, Hyde set out to eliminate the wash water from this process. The company also installed energy-efficient lighting.

\section{The Company}

Hyde Tools is a Massachusetts-based manufacturer of cutting tools employing 300 people. Hyde's industrial line, comprising machine blades, saw blanks, and hand knives, sells under its own brand name and other labels. Hyde's trade products capture about $20 \%$ of the do-it-yourself market and are found in many hardware stores.

\section{The Approach}

Hyde's purchasing and environmental manager, Doug DeVries, knew of a company in Massachusetts that had eliminated wastewater discharge from its plating and tumbling processes. He decided to implement a similar zero-water discharge goal at Hyde. To accomplish this goal, plant engineers and DeVries drafted a plan to reduce hazardous substance use and eliminate wastewater discharge. At the same time, Hyde's president and chief executive officer introduced Hyde's Total Employee Involvement Program. The program is based on total quality management principles and involves all employees in improving Hyde's manufacturing operations at their Southbridge, Massachusetts, plant.

Each workday at Hyde begins with a 5-minute team meeting in which employees discuss the activities of the day before, such as what went right, how it could be improved, what went wrong, and how to prevent it from happening again. These teams have been instrumental in the implementation process of pollution prevention changes in areas such as degreasing, heat treating, and vibratory finishing. Hyde also operates an employee suggestion program; several suggestions have resulted in economic and environmental benefits for the company.

\section{Project Description}

After considerable technical analysis, Hyde determined that in-process recycling could eliminate the wastewater problem from the potassium chloride heat-treating process. Hyde engineers and production workers installed a system to remove quench oils from rinse tanks and return the oil back to the quench tank. Five hundred gallons of water from the rinse tank are recycled back into the wash tank to make up for evaporative losses. Then, 500 gallons of fresh water are added to fill the rinse tank. Hyde has completely eliminated wastewater discharge from this operation and recycles all the quench oil from the quench tank back into the process. Hyde periodically distills and filters the quench oil to remove impurities.

Hyde also upgraded its lighting from old fluorescents to new high-pressure sodiumvapor and metal-halide fixtures. Even though Doug DeVries was confident that the retrofit would yield substantial savings, he still insisted on trying it out in one area. 
The workers had the option of switching to the original lighting after a 6-month period. When Hyde experimented by turning on the old lights after 6 months, employees disapproved. The new lights had made it possible to see specks of dirt on equipment that caused defects in the blades.

\section{Installation and Operation}

Hyde spent $\$ 25,055$ to install the wastewater and quench oil recycling system and train workers. The lighting retrofit cost $\$ 98,000$, including labor, with $\$ 48,000$ covered by Massachusetts Electric, the local utility.

\section{Economic Benefits}

Savings from the wastewater recycling for the potassium chloride heat-treating process include $\$ 3,500$ in quench oil purchases and $\$ 66,370$ in avoided costs such as wastewater treatment, testing, and sewer fees.

With the new lighting, the quality of the work improved. Hyde estimates that this improved quality is worth another $\$ 25,000$ to the company. The annual energy savings equals approximately $\$ 48,000$, resulting in a payback of about 1 year. 
Aqueous Cleaning Sustem Eliminates the Use of Chemicals and Saves Energu

TECHNOLOGY

High-pressure aqueous cleaning system

BENEFITS

Annual savings of $\$ 110,000$

APPLICABLE SIC CODE 3471

\section{SOURCE OF CASE STUDY}

North Carolina Department of Environment, Health, and Natural Resources; Office of Waste Reduction Case Studies, December 1994.

\section{The Challenge}

The Ilco Unican facility in Rocky Mount, North Carolina, produces more than 1.5 million blank keys each day. During fabrication, a residue of medium-grade cutting oil is left on the keys. This residue must be removed before the keys can undergo further processing. Ilco Unican had been using $1,1,1$, trichloroethane in a vapor degreaser to clean the keys. To eliminate the use of the organic solvent degreaser, llco Unican designed a new aqueous cleaning system.

\section{Project Description}

The aqueous cleaning system uses a highpressure spray of hot water to wash the keys and high-pressure air to dry them. No chemical cleaners are added. The spray nozzles are placed so that the keys spin on rods to allow thorough cleaning between rows. The water in the system is recirculated and cleaned by an oil skimmer. Because the water is recycled, no more than 25 gallons a day have to be added to the system. Screens are used on the nozzles to keep them free from fine metal chips that may have been present on the keys.

\section{Energy Savings}

The efficiency of the new system has cut the plant's water use in half and reduced the energy used in the cleaning phase by almost $95 \%$.

\section{Environmental Benefits}

Ilco Unican's yearly consumption of almost 200,000 pounds of $1,1,1$ trichloroethane has been completely eliminated.

\section{Economic Benefits}

The new washer cost $\$ 119,327$ and had a payback period of 1.08 years. The project is saving Ilco Unican more than $\$ 110,000$ a year. Approximately $\$ 60,000$ per year of that savings is coming from the elimination of $1,1,1$ trichloroethane and its disposal. The energy savings total another $\$ 25,000$ a year, while the rest of the savings is in water and labor reductions. Offsetting liability associated with chemical treatment was not considered in the cost analysis but was another benefit of the process change.

For more information, contact Brian Wells, Project Engineer, at (919) 725-1331. 


\section{San Diego Universily moustrial lassessnent center}

\section{The Challenge}

From May 1993 through April 1994, a transducer manufacturer consumed 29,806 million Btu of energy at a cost of $\$ 625,777$. Electricity accounted for 22,953 million Btu and cost the company $\$ 579,645$. The remaining energy demand was met by natural gas. The IAC at San Diego State University performed an energy assessment in April 1994 and identified several energy efficiency opportunities that now save the company more than $\$ 213,000$ annually.

\section{The Company}

The plant, which employs 400 people in a one-shift operation, manufactures $\$ 18$ million worth of linear position and pressure transducers each year. Electricity is used for the majority of the processrelated equipment, air conditioning, and lighting. Natural gas is used for space heating and hot water.

\section{IAC Recommendations}

- Replacing the plant's five chillers with a single 400-ton unit would conserve 4600 million Btu per year and save $\$ 117,000$ annually.

- Replacing lamps and ballasts, installing reflectors in fluorescent fixtures, removing half of the lamps in each fluorescent lighting fixture, reducing the lighting operating hours for unoccupied areas, and other lighting improvements would save the company $\$ 84,000$ per year in electricity and maintenance costs.

- Replacing 14 motors between 3 and 50 horsepower, as they burn out, with high-efficiency ones would save 40 million Btu per year and nearly $\$ 1,000$ annually.
Turning off the hot water circulation pump when the boilers are not in use would annually save the company both 270 million Btu of electricity and $\$ 6,700$.

- Repairing leaks in the compressed air line would save about $\$ 3,800$ annually.

Insulating hot water lines would save the company 56 million Btu of natural gas per year and about $\$ 380$ annually.

\section{Energy Savings}

The company saves a total of 8242 million Btu in electricity and natural gas by implementing all the changes suggested by the San Diego State University IAC.

\section{Economic Benefits}

The company realizes annual cost savings of $\$ 117,000$ by replacing several chillers (left as backups) with a single unit sized to match the system load. This measure has a 2-year payback. The company achieves additional savings of nearly $\$ 84,000$ per year through lighting efficiency improvements. By using a time clock controller to reduce the operating hours of hot water circulation pumps, insulating hot water lines, replacing standard motors with high-efficiency ones, and repairing leaks in the compressed air line, the company also saves $\$ 12,000$ per year.

In total, the manufacturer saves more than $\$ 213,000$ annually after acting on recommendations made by the IAC. The cost to implement the recommendations was about $\$ 385,000$, leading to a payback of less than 2 years.

\section{COMPANY}

Manufacturer of transducers

AUDIT DATE

April 1994

COST SAVINGS

$\$ 213,000$ annually

ENERGY SAVINGS

8242 million Btu annually 


\section{Compą Computer Corporation}

\section{Energy-Efficient Rerrofits Result in Significant Cost Savings}

TECHNOLOGY

Energy-efficient lighting and HVAC retrofits

\section{BENEFITS}

$\$ 1$ million annual energy savings

APPLICABLE SIC CODE 3571

\section{SOURCE OF CASE STUDY}

The Compaq Experience:

Corporate Dynamics

\& Energy Efficiency,

IRT Environment, Inc., Aspen, Colorado, 1993.

\section{The Challenge}

Compaq Computer Corporation in Houston, Texas, experienced tremendous growth during its early years in the $1980 \mathrm{~s}$. It increased exponentially in staffing and profits-but with the growth came growing pains.

With so many more employees producing so many more computers, the company needed to expand from its original 20,000 square feet. In a matter of months, Compaq went to 160,000 square feet, but it was soon apparent that the company needed more space. The founders took a long-term approach and decided to buy the land and build the buildings the company needed. In total, they bought about 149 acres northwest of downtown Houston and planned for more than 1 million square feet of office and manufacturing space.

This raw land gave Compaq the opportunity to incorporate as many energyefficient technologies and systems as it could. The company believed in being a good corporate citizen and neighbor, and it believed in controlling its share of pollution through the wise use of energy resources. Compaq's new facilities adopted energyefficient lighting, correctly sized cooling systems, high-quality windows, and even its own waste-to-energy plant. In total, Compaq's energy efficiency initiatives resulted in estimated energy savings of $25 \%$ or $\$ 1$ million per year.

\section{The Company}

Started in 1982, Compaq Computer Company raced to the forefront of the personal computer market. During the period from 1983 to 1987, the company saw growth unprecedented by American businesses. Compaq's staff grew from its 3 founders to more than 1800 employees by 1986. During 1983-the first year of production-the company's sales of $\$ 111$ million were the highest first-year sales in the history of American business. By 1987, Compaq passed the billion dollar mark in sales, and did so faster than any other company in history.

Compaq still commands a large share of the PC and laptop market. The basics on which the company was founded-building a quality computer with quality support to back it up—still hold true today and keep Compaq a strong and viable company.

\section{The Approach}

Under the direction of the facilities manager at that time, Ron Perkins, Compaq took the initiative in implementing energy efficiency without state, Federal, or utility incentives. Being able to work with the architects allowed Perkins to choose a basic structure design that would be amenable to energy efficiency technologies as well as fit the other criterion: to give the employees a working environment that stimulated creativity and enhanced individual effort and productivity.

\section{Project Description}

The lighting fixtures Compaq had been using in their buildings cost about $\$ 94$ and used about 176 watts. Then Perkins heard of a product marketed by The Lighting Corporation in Chicago that offered specular silver reflective film over the fascia, a single electronic ballast, and two high-colorrendering F40-watt, $3500 \mathrm{~K}$ Ultralume lamps. These fixtures cost $\$ 134$, but used only 70 watts to deliver the same light output. Compaq bought 4000 of these fixtures to light two buildings. This upgrade saved the company more than $\$ 60,000$ in energy per year. At a marginal cost of $\$ 160,000$, payback was 2.7 years.

This shift to efficient troffers was the major lighting advance, but Compaq also installed high-intensity discharge, high- 
pressure sodium lamps for garage and street lighting. In lobbies and other high-profile areas, the high wattage incandescents were overheating and burning out frequently. These lamps were replaced with compact fluorescents.

Compaq also saved energy and money by addressing the cooling systems. By using better cooling towers for its central chilling plant, the company saved $\$ 90,000$ worth of energy. Removing eight secondary pumps from the original (and over-designed) HVAC system saved 240 horsepower, which translated into more than $\$ 100,000$ per year. The piping for the centralized cooling systems was doubled in diameter, which reduced friction and allowed for smaller pumps to be used. In fact, downsizing the pumps paid for the entire cost of doubling the pipe size.

Compaq also used low-e glass in its building atriums, which cut down on heating and cooling load. The company even installed a waste-to-energy plant capable of generating 1000 horsepower of output that provided steam for the factory and the chillers. At a cost of $\$ 1.2$ million, the payback period was 2.8 years.

\section{Benefits}

In all, Compaq Computer Corporation saved about $25 \%$ of its annual energy bill, which amounts to approximately $\$ 1$ million per year.

For more information, contact The Results Center, Aspen, Colorado, at (970) 927-3155. 
Alleernative Commuting

Saves Fuel and
Reduces fir Pollution

TECHNOLOGY

Alternative commuting

BENEFITS

Fuel savings, reduced greenhouse gas emissions, less traffic congestion

APPLICABLE SIC CODE 5139

SOURCE OF CASE STUDY

City of Portland

Energy Office,

Case Studies on BEST

Business Award Winners.

\section{The Challenge}

NIKE, Inc., a sport shoe and fitness company, has its corporate headquarters in the Portland, Oregon, area. It also has a retail outlet, NIKE TOWN, located in downtown Portland. Seventy-five people work at NIKE TOWN, and most of them used to drive to work alone. Since 1992, NIKE TOWN has reduced employee commuting trips at its facilities. NIKE's efforts encourage and reward almost any transit alternative to driving to work alone. The results are reduced fossil fuel use, air pollution, and traffic congestion.

\section{Project Description}

NIKE offers employees a $\$ 1$ voucher (a "NIKE Buck") every day they bike, run, walk, or skate to work. NIKE Bucks are good at the employee store, the cafeteria, and the company's child care center. Each carpooling employee also gets a NIKE Buck in addition to choice parking spots in NIKE's parking lots.

NIKE has an incentive for public transit, too. It joined forces with Tri-Met to provide reduced cost transit passes for employees. These passes are available for as much as $75 \%$ off the regular price. The value of the discounts is equal to the NIKE Buck option (\$21 per month).

\section{Energy and Environmental Benefits}

Before the company started promoting transit alternatives, only a few NIKE TOWN employees rode the bus or biked to work. Now they have 2 car pools, 27 bus riders, and 20 employees who bike, run, walk, or skate to work each day. These commuting changes at NIKE TOWN impact downtown traffic levels. Changes by NIKE TOWN employees have eliminated trips by 26 singleoccupancy vehicles per day. During one year, that adds up to more than 6700 avoided trips. NIKE TOWN's employees average 20 miles for a round-trip commute, so they have reduced vehicle travel by more than 135,000 miles per year. Fewer car miles mean less gasoline use and reduced air pollution.

Assuming that a vehicle averages a city mileage of 18 miles per gallon, the trips that NIKE TOWN employees now avoid save more than 7500 gallons of gasoline per year. That equals nearly 4700 pounds of air pollutants-carbon monoxide, unburned hydrocarbons, and oxides of nitrogen. It also results in a reduction of $\mathrm{CO}_{2}$ emissions by more than 150,000 pounds per year.

\section{Additional Benefits}

In early 1993, NIKE TOWN received a "BEST Innovation Award" issued jointly by the City of Portland and the Association for Portland Progress (APP). The award recognized its innovative transit alternative activities. Using muscle power instead of fossil fuel to get to work helps in many 
ways. NIKE TOWN employees are now more fit than before. And there's cleaner air, less congestion on the roads, and more space for downtown business customers to park.

Employees are having more fun, too. One employee who never thought she would share a ride with anyone started carpooling for the NIKE Bucks. Now she enjoys it so much that she would continue carpooling even if the incentives were discontinued.

\section{Impact on Company}

Employee transportation may not seem to be part of the day-to-day operations of a business. However, the stress of driving and parking can impact employees' work. Employees who use the bus or another transit alternative to commute may be more productive.

For more information about NIKE's innovative transit efforts, contact Julie Papen at (503) 671-2961.
There are six easy steps

to helping your employees use an alternative commuting method:

Publicly state top management's commitment to mass transit, carpooling, and other alternatives.

Establish an employee transit coordinator and make it a high-profile appointment.

Offer discounted transit passes and other rewards for alternative commuting to all employees.

Provide parking spaces for bicycles and reserve some choice parking spaces for carpools.

5

Stop paying for (or sell rights to) freed-up parking spaces, if any.

Track and publicize the results (for management and other employees). 


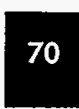

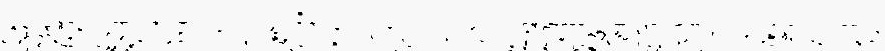


Appendix 


\section{Industrial Assessment Centers}

CONTACT

Charles Glaser

Program Manager,

Industrial Assessment Center

Program

Office of Industrial

Technologies

Energy Efficiency and

Renewable Energy

U.S. Department of Energy

(202) 586-1298
In 1978, the Department of Energy's Office of Industrial Technologies assumed responsibility for an assessment program, then known as the Energy Analysis and Diagnostic Centers (EADC) program, from the U.S. Department of Commerce. The EADC program's assessments provided manufacturers with recommendations to help them control costs and improve energy efficiency at their plants. In 1993, DOE teamed with the EPA to expand the program to assess productivity and industrial waste as well as energy. Now qualified to conduct both energy audits and productivity and waste analyses, the centers are known as Industrial Assessment Centers (IACs). There are currently 30 IACs in operation, each conducting 30 assessments per year.

IACs operate out of engineering schools at major universities across the country. Teams of engineering faculty and top engineering students perform one-day site assessments after they have gathered extensive pre-audit data. The audit team then prepares a report for the manufacturer that includes information about the plant's energy use, processes, and other operations. In addition, each report describes opportunities for improving efficiency and includes engineering designs, implementation costs and simple payback for each opportunity presented.

Small- and medium-sized manufacturers often lack the in-house staff or expertise to identify specific waste minimization and energy efficiency improvements. By offering assessments free of charge, the IAC program is helping these manufacturers improve their bottom line and contribute to overall U.S. manufacturing competitiveness.

The IAC program benefits don't stop with providing cost-saving opportunities to manufacturers. Students also benefit by receiving training in energy and waste management practices and hands-on experience in a range of manufacturing operations. Manufacturers and industry as a whole gain a pool of ideal candidates for engineering positions. Hiring these skilled students can sharpen a manufacturer's competitive edge. At the close of 1994 , approximately 1000 students had received audit training.

\section{Energy Saved (MMBtu) by Recommendation Types that Were Implemented}

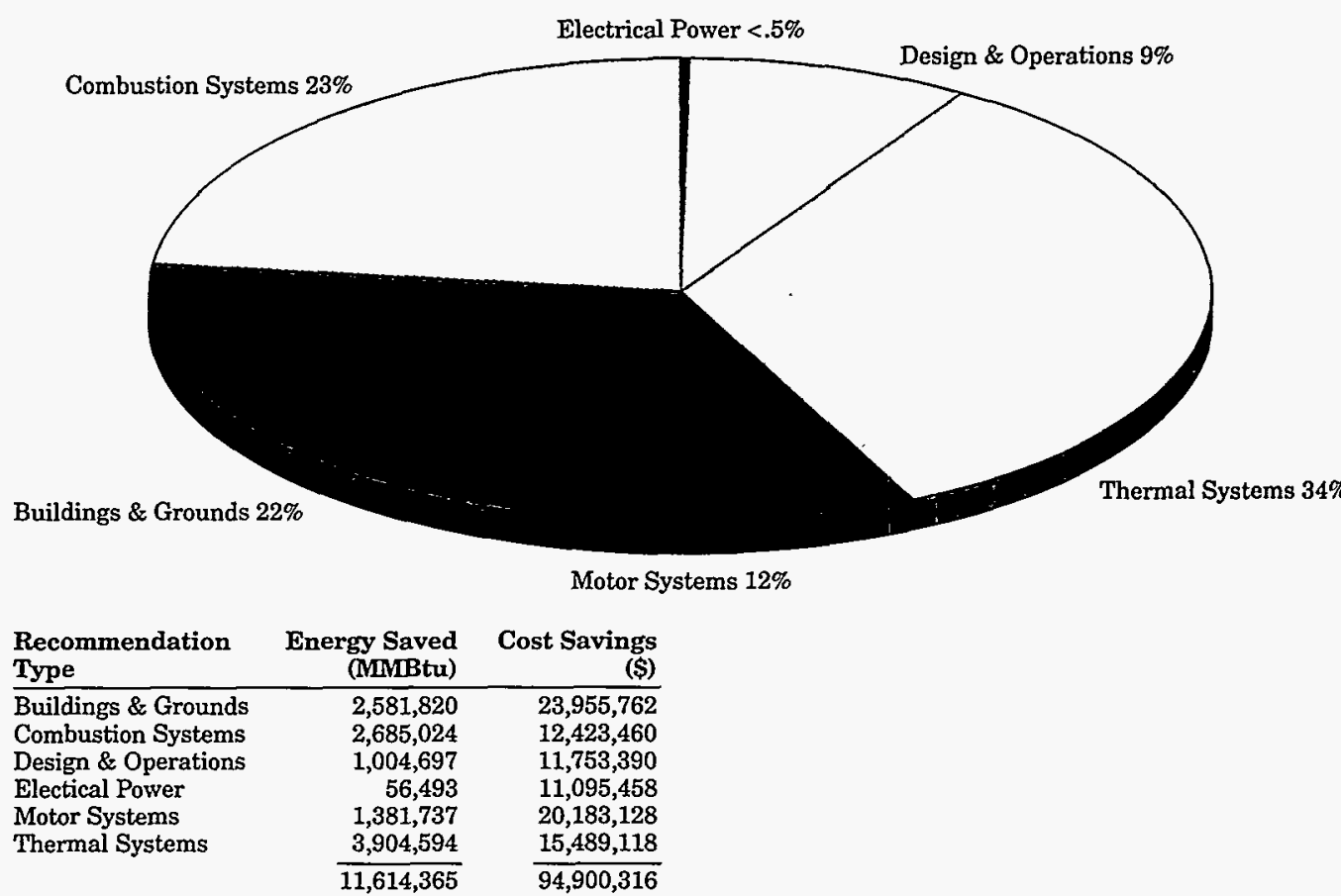




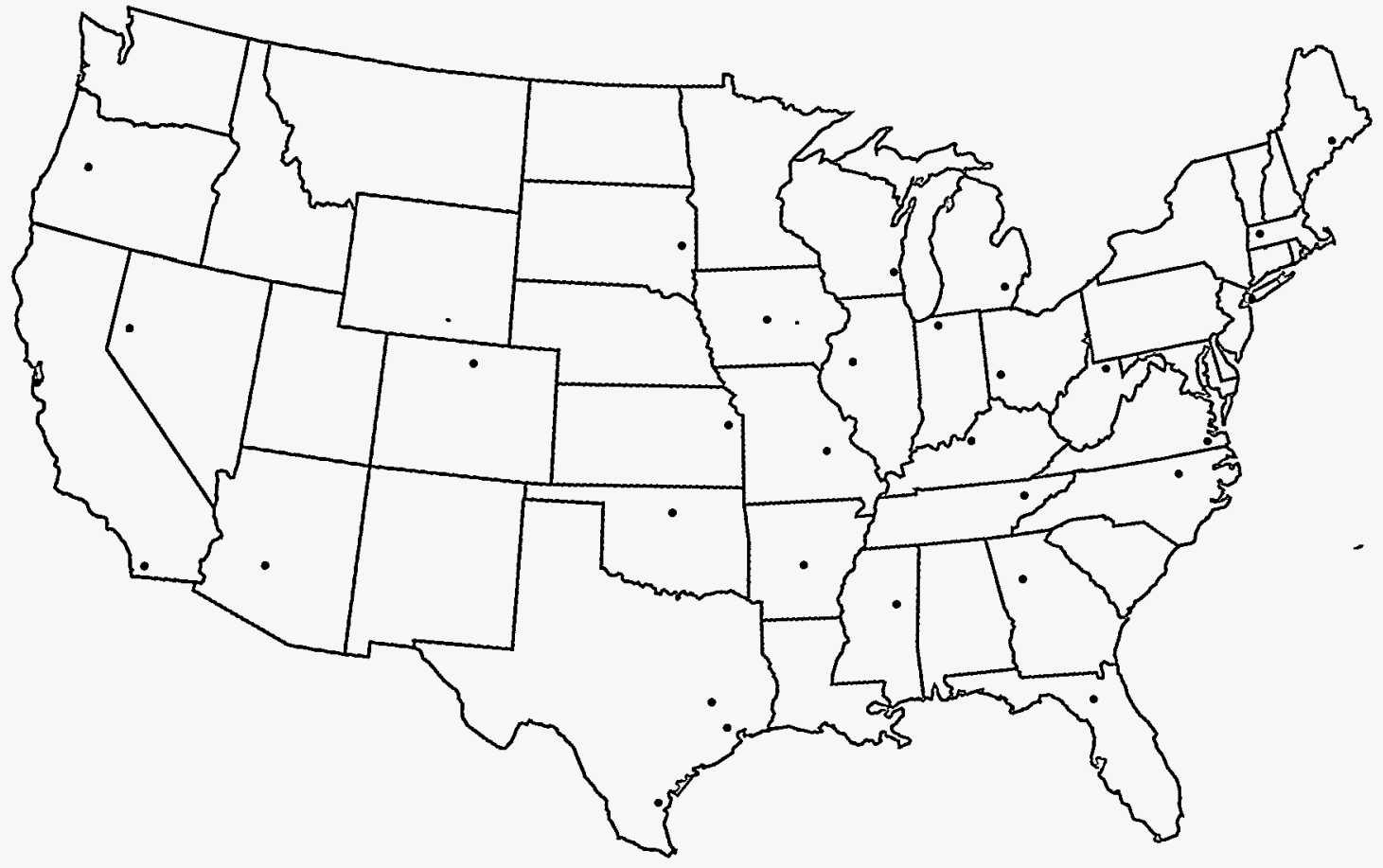

\section{Industrial Assessment Centers and Contacts:}

\section{Arizona State University \\ David McCarthy \\ (602) $965-5604$ \\ Robert Sears \\ (602) 965-2889}

\section{Bradley University}

Max Wessler

(309) 677-2710

Colorado State University

Harry Edwards

(970) 491-5317

Michael Kostrzewa

(970) 491-7709

\section{Georgia Institute of}

Technology

Michael Brown

(404) 894-6107

\section{Hofstra University}

Manush Raship

(516) 463-5063

\section{Iowa State University}

Gregory Maxwell

(515) 294-8645

Mississippi State University

Richard Forbes

(601) 325-7312

\section{North Carolina State}

University

Herbert Eckerlin

(919) 515-5227
Ohlahoma State University

Clint Christenson

(405) 744-6055

Eric Woodroof

(405) 744-9146

Old Dominion University

Robert Michel

(804) 683-4591

Oregon State University

Dwight Bushnell

(503) 737-2575

San Diego State University Asfaw Beyene

(619) 594-6207

San Francisco State

University

Dr. Shy-Sheng P. Liou

(415) 338-7733

Ronald Trauner

(415) 338-6203

South Dakota State

University

Michael Twedt

(605) 688-4303

\section{Texas A\&M University}

James Eggebrecht

(409) 845-1508
Texas A\&M UniversityKingsville

Mario Medina

(512) 595-2114

West Virginia University B. Gopalakrishnan (304) 293-4607

University of Arkansas at Little Rock Mamdouh Bakr (501) 569-8228

University of Dayton

Norman Hecht

(513) 229-4343

University of Florida

at Gainesville

Dale Kirmse

(904) 392-0862

University of Kansas

Brian Burke

(913) 864-4380

University of Louisville

Robert Stewart

(502) 852-6340

University of Maine

Mark Armstrong

(207) 581-2329

University of Massachusetts

Dragulb Kosanovic

(413) 545-4216
University of Michigan

Sanjay Agrawal

(313) 763-7471

University of Missouri-

Rolla

John Sheffield

(314) $341-4690$

University of Nevada-Reno

Andrzej Trzynadlowski

(702) 784-1490

Yunus Cengel

(702) 784-1690

University of Notre Dame

William Berry

(219) 631-6102

University of Tennessee

William Johnson

(615) 974-5307/5115

University of Wisconsin at Milwaukee

Arun Garg

(414) 229-6240 